\title{
Damage and rupture dynamics at the brittle-ductile transition: The case of gypsum
}

\author{
N. Brantut, ${ }^{1}$ A. Schubnel, ${ }^{1}$ and Y. Guéguen ${ }^{1}$ \\ Received 28 April 2010; revised 20 October 2010; accepted 22 November 2010; published 19 January 2011. \\ [1] Triaxial tests on gypsum polycrystal samples are performed at confining pressure $\left(P_{\mathrm{c}}\right)$ \\ ranging from 2 to $95 \mathrm{MPa}$ and temperatures up to $70^{\circ} \mathrm{C}$. During the tests, stress, strain, \\ elastic wave velocities, and acoustic emissions are recorded. At $P_{\mathrm{c}} \leq 10 \mathrm{MPa}$, the \\ macroscopic behavior is brittle, and above $20 \mathrm{MPa}$ the macroscopic behavior becomes \\ ductile. Ductile deformation is cataclastic, as shown by the continuous decrease of \\ elastic wave velocities interpreted in terms of microcrack accumulation. Surprisingly, \\ ductile deformation and strain hardening are also accompanied by small stress drops \\ from 0.5 to $6 \mathrm{MPa}$ in amplitude. Microstructural observations of the deformed samples \\ suggest that each stress drop corresponds to the generation of a single shear band, \\ formed by microcracks and kinked grains. At room temperature, the stress drops are not \\ correlated to acoustic emssions (AEs). At $70^{\circ} \mathrm{C}$, the stress drops are larger and systematically \\ associated with a low-frequency AE (LFAE). Rupture velocities can be inferred from the \\ LFAE high-frequency content and range from 50 to $200 \mathrm{~m} \mathrm{~s}^{-1}$. The LFAE amplitude also \\ increases with increasing rupture speed and is not correlated with the amplitude of the \\ macroscopic stress drops. LFAEs are thus attributed to dynamic propagation of shear bands. \\ In Volterra gypsum, the result of the competition between microcracking and plasticity \\ is counterintuitive: Dynamic instalibilities at $70^{\circ} \mathrm{C}$ may arise from the thermal \\ activation of mineral kinking.
}

Citation: Brantut, N., A. Schubnel, and Y. Guéguen (2011), Damage and rupture dynamics at the brittle-ductile transition: The case of gypsum, J. Geophys. Res., 116, B01404, doi:10.1029/2010JB007675.

\section{Introduction}

[2] At low pressure and temperature, typically at shallow depth in the crust, rocks accommodate deformation in a brittle manner, by fracturing and faulting. With increasing depth, i.e., with increasing lithostatic pressure and ambient temperature, rocks experience a transition from brittle to ductile behavior. The existence of such a transition has several important geophysical and geodynamical consequences. It can be used to estimate the maximum strength of the lithosphere [e.g., Brace and Kohlstedt, 1980], and it has been interpreted as the transition from seismic to aseismic behavior of faults [Sibson, 1982]. The identification of the physical processes involved across the brittleductile transition provides useful keys to understand and extrapolate laboratory data to field scale, and in particular to get insights into the seismic behavior of faults.

[3] The brittle regime consists in the formation of a macroscopic fracture or fault in which most of the deformation is localized. It is characterized by a strain softening (or, equivalently, a slip weakening) mechanical behavior; such a feature has been used by Jaeger and Cook [1969] as

\footnotetext{
${ }^{1}$ Laboratoire de Géologie, École Normale Supérieure, CNRS UMR 8538, Paris, France.

Copyright 2011 by the American Geophysical Union. 0148-0227/11/2010JB007675
}

a definition of the brittle regime. Microscopically, the processes involved are microcrack opening and coalescence, as well as friction on asperities. These microprocesses can be recognized experimentally by (1) dilatancy prior to rupture [e.g., Brace et al., 1966], (2) acoustic emission (AE) activity and localization [e.g., Scholz, 1968; Mogi, 1968; Lockner et al., 1992], and (3) a decrease in $P$ and $S$ wave velocities as microcracks accumulate [e.g., Gupta, 1973; Lockner et al., 1977].

[4] The ductile regime can be defined as the ability to undergo large strains without fracturing of the rock [Paterson and Wong, 2005]; it is thus characterized by a homogeneously distributed deformation throughout the rock at the macroscopic scale (typically of the order of 1 to $10 \mathrm{~cm}$ in laboratory tests). Ductile deformation is generally associated with strain hardening [e.g., Evans et al., 1990]. At the microscopic scale, strain localization can occur, and the associated microprocesses can be of two types. They can involve mainly cracking, in which case the rock accumulates distributed microcracks without any macroscopic rupture. This behavior, called cataclastic flow [Evans et al., 1990; Paterson and Wong, 2005], is commonly met at elevated pressure and low temperature in quartzo-feldspathic aggregates [e.g., Handin and Hager, 1957; Hadizadeh and Rutter, 1983; Tullis and Yund, 1992; Wong et al., 1997]. Cataclastic flow generally produces a significant AE activity [e.g., Baud et al., 2004] and induces 

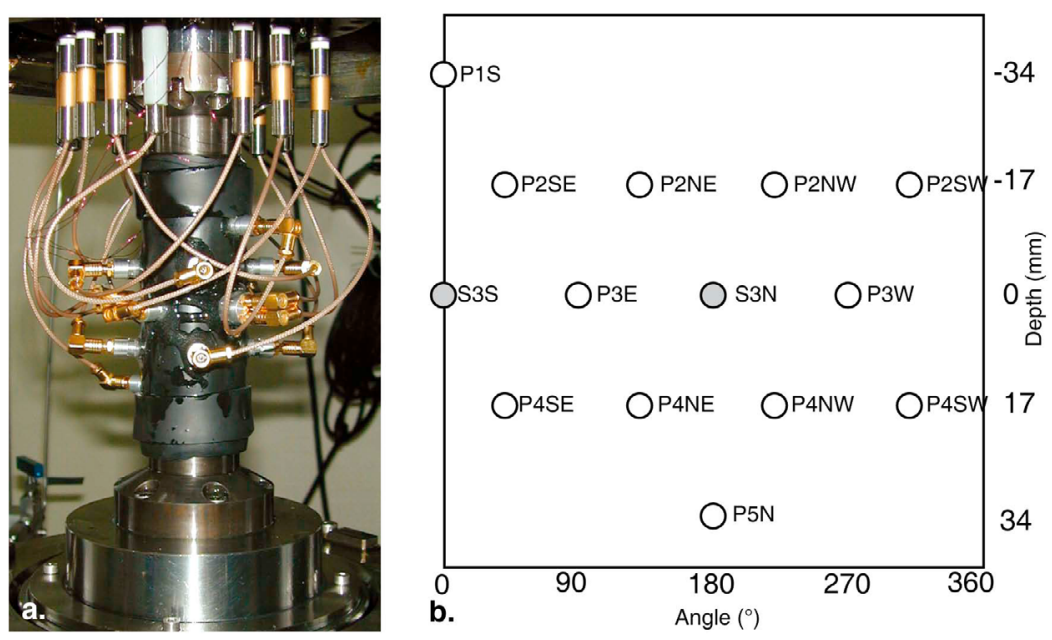

Figure 1. Photograph of the sample assembly and typical sensor map. (a) All sensors are connected to the outside through high-voltage coaxial feedthroughs. (b) The typical sensor map. The gray circles are $\mathrm{SH}$ wave transducers. There might be minor variations of the sensor map depending on the test, but the sensor position is kept constant as displayed here.

changes in $P$ and $S$ wave velocities [Ayling et al., 1995]. On the other hand, the microprocesses can also be plastic (either intragranular or intergranular) when temperature is sufficiently high. In between those two end members (either cataclastic or plastic flow), a mixed behavior is observed; it has been extensively documented in carbonate rocks such as Solnhofen limestone or Carrara marble [Heard, 1960; Fredrich et al., 1989; Evans et al., 1990; Baud et al., 2000; Schubnel et al., 2005; Paterson and Wong, 2005].

[5] The physical basis of the brittle-ductile transition in dry rocks relies on two main factors. First, an increase in confining pressure tends to hamper microcrack opening and coalescence. Second, an increase in temperature activates dislocation mobility and diffusion processes. The coexistence of these mechanisms over a significant pressuretemperature range implies that the brittle-ductile transition is rather smooth and continuous [Evans et al., 1990].

[6] In order to compare the brittle-ductile transition to the seismic-aseismic transition, time and length scales need to be introduced. At the submillimeter scale, dynamic microprocesses such as microcrack propagation, but also twinning [e.g., Laughner et al., 1979] and dislocation motion [e.g., Weiss and Grasso, 1997], produce elastic waves or AE, at typical frequencies of around $1 \mathrm{MHz}$. Indeed, from a material science point of view, deformation is always localized at some particular length and timescale. AE signals have been used to characterize damage during rock deformation [e.g., Scholz, 1968; Mogi, 1968; Lockner et al., 1992] even in the ductile regime and in the absence of stick-slip [e.g., Baud et al., 2004; Fortin et al., 2006]. Thus, the record of $\mathrm{AE}$ during deformation cannot be systematically understood as the signature of a seismic behavior. On the other hand, at the macroscopic scale, Brace and Byerlee [1966] suggested that stick-slip motion could be an analogue to seismic slip; stick-slip is a frictional instability that occurs on macroscopic fractures in laboratory samples, typically of the order of $10 \mathrm{~cm}$. The elastic waves generated by stick-slip events can be recorded either by acoustic emission transducers [e.g., Thompson et al., 2005] or by photoelasticity [e.g., Rosakis et al., 1999] and can be seen as analogues to earthquake waves. Thus, the distinction between a seismic behavior versus an aseismic behavior could be made by considering the characteristic size of the dynamic process occurring. If it involves a length scale much longer than the grain size, e.g., up to the sample size in the case of stick-slip, then a dynamic event in the laboratory can be considered as an analogue to a seismic event in nature. Otherwise, if the length scale remains linked to the grain size (e.g., in the case of twinning), the dynamic process cannot be considered as an analogue to earthquakes.

[7] In this paper, we aim at better understanding the relationship between the brittle-ductile and the seismicaseismic transition by investigating experimentally the dynamics of the deformation processes in gypsum aggregates at various pressures and temperatures. The particular rock chosen for our investigations is a natural gypsum polycrystal from Volterra, Italy. Although it has been intensively studied for its chemical reactivity (gypsum dehydration occurs at relatively low temperature $\sim 100^{\circ} \mathrm{C}$ ), gypsum deformation processes are still poorly known [Turner and Weiss, 1965; Stretton, 1996; Barberini et al., 2005]. The study of gypsum properties can be of interest in itself, as a caprock in oil reservoirs [e.g., Brown, 1931] and a constituent of fault zones in the Jura Mountains and the Alps [e.g., Heard and Rubey, 1966; Laubscher, 1975; Malavieille and Ritz, 1989]. Here, the choice of gypsum is rather dictated by the fact that it can be considered as an analogue of other, more ubiquitous minerals of the crust. Indeed, its crystal structure can be viewed as an analogue of hydrous phyllosilicates, for two reasons: (1) It is a layered structure containing water molecules that form a perfect cleavage plane, and (2) it can dehydrate to produce denser products (bassanite at around $100^{\circ} \mathrm{C}$ and anhydrite at around $140^{\circ} \mathrm{C}$ ). In this study, we investigate gypsum's deformation processes using a triaxial deformation apparatus, at various confining pressures from $2 \mathrm{MPa}$ to $95 \mathrm{MPa}$ and at temperatures ranging from $25^{\circ} \mathrm{C}$ to $70^{\circ} \mathrm{C}$. No dehydration is involved in this temperature range, so that the phenomena 


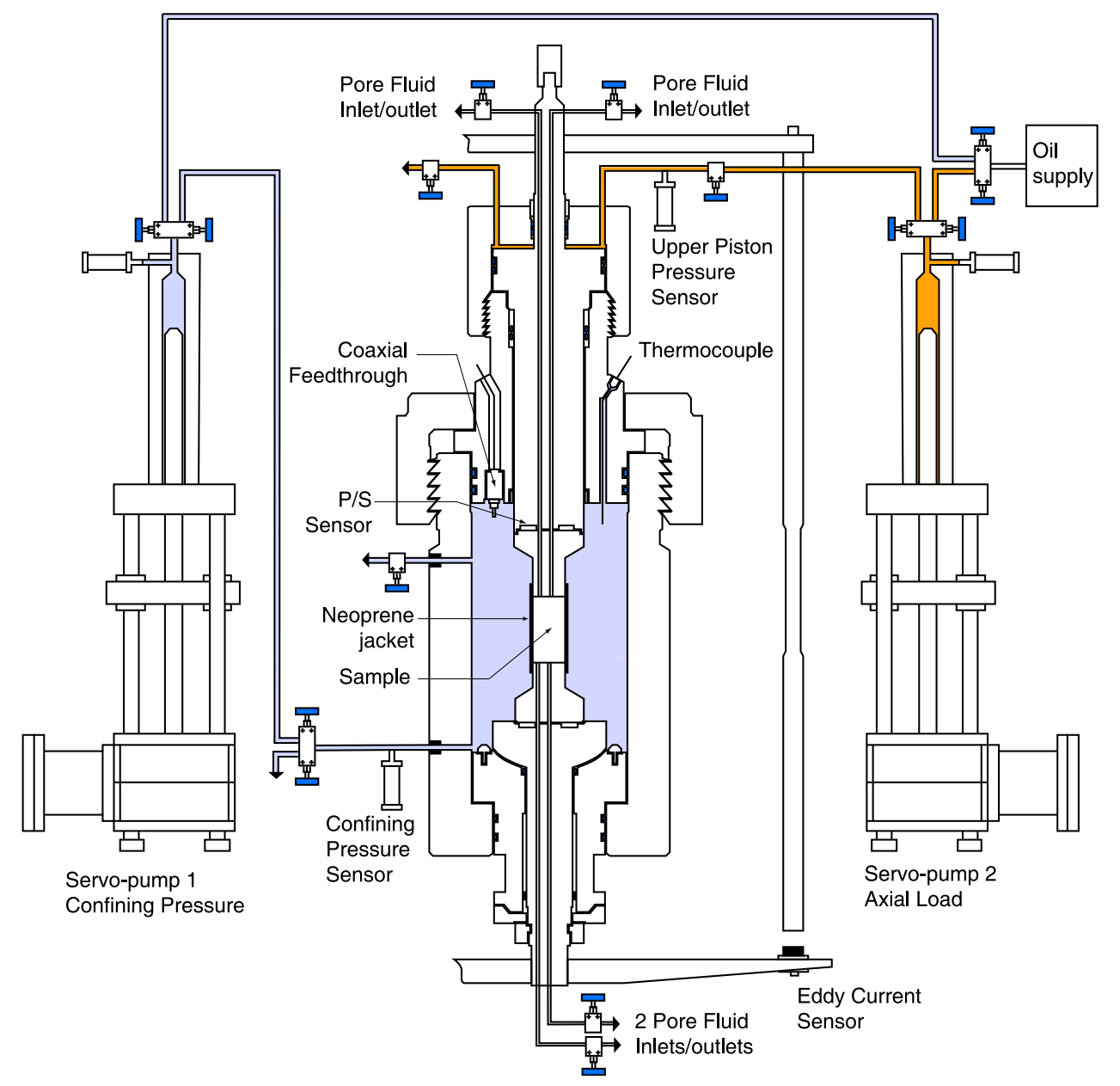

Figure 2. Schematic of the experimental apparatus. Axial load is measured by knowing the oil pressure inside the upper piston and the area ratios. Axial deformation is measured by the mean of three external displacement transducers, and then corrected from the machine stiffness. All experiments were performed vented to the atmosphere.

we expect are only thermomechanical processes. Along with stress-strain curves, we regularly measure $P$ and $S$ wave velocity and continuously record AEs during deformation in order to have access to the dynamics of the deformation processes.

\section{Starting Material and Experimental Setup}

\subsection{Starting Material and Sample Preparation}

[8] The material used in our experiments is natural gypsum alabaster from Volterra, Italy, the same rock that was previously used by other authors for deformation and dehydration experiments [Heard and Rubey, 1966; Ko et al., 1995; Olgaard et al., 1995; Stretton, 1996; Ko et al., 1997; Milsch and Scholz, 2005]. The initial microstructure consists in a relatively fine-grained (from $10 \mu \mathrm{m}$ to $200 \mu \mathrm{m}$ ) polycrystal (Figures $6 \mathrm{a}$ and $6 \mathrm{~b}$ ). The initial porosity of the material was estimated by comparing the weight of a watersaturated sample with the weight of the same sample dried in a vacuum at $40^{\circ} \mathrm{C}$ during 4 days. Using a matrix density of $2305 \mathrm{~kg} \mathrm{~m}^{-3}$ (pure gypsum) and a water density of $10^{3} \mathrm{~kg}$ $\mathrm{m}^{-3}$, a porosity value of $\leq 0.5 \%$ was calculated. All the samples were cored in the same block in the same direction. Sample dimensions were $85 \mathrm{~mm}$ in length and $40 \mathrm{~mm}$ in diameter. Initial $P$ wave velocity of the whole block was measured at room pressure and temperature, and was around $5250 \mathrm{~m} \mathrm{~s}^{-1}$, varying from $5000 \mathrm{~m} \mathrm{~s}^{-1}$ to $5300 \mathrm{~m} \mathrm{~s}^{-1}$ depending on the location and on the direction of measurement; anisotropy is thus generally less than $\sim 5 \%$. After coring, the samples were ground to obtain perfectly parallel ends (with a precision of $\pm 10 \mu \mathrm{m}$ ). They were then dried in a vacuum at $\sim 40^{\circ} \mathrm{C}$ for a few weeks prior to the tests.

[9] The samples were then jacketed in a perforated neoprene sleeve, and 12 to 14 piezoelectric transducers (PZTs) were directly glued onto the samples' surface (see Figure 1a). Each PZT is made of a piezoelectric crystal (PI ceramic P1255), sensitive either to $P$ waves (normal to the interface, cylinders of $5 \mathrm{~mm}$ in diameter, $2 \mathrm{~mm}$ in thickness) or to $S$ waves (along the interface, platelets of $5 \times 5 \times 1 \mathrm{~mm}$ ), encapsulated in an aluminium holder. The principal resonant frequency of these sensors is around $1 \mathrm{MHz}$. The electric connection of the signal is ensured by a mechanical contact between a stainless steel piston and the core of a coaxial plug. In the case of $S$ wave sensors, the crystal is glued 


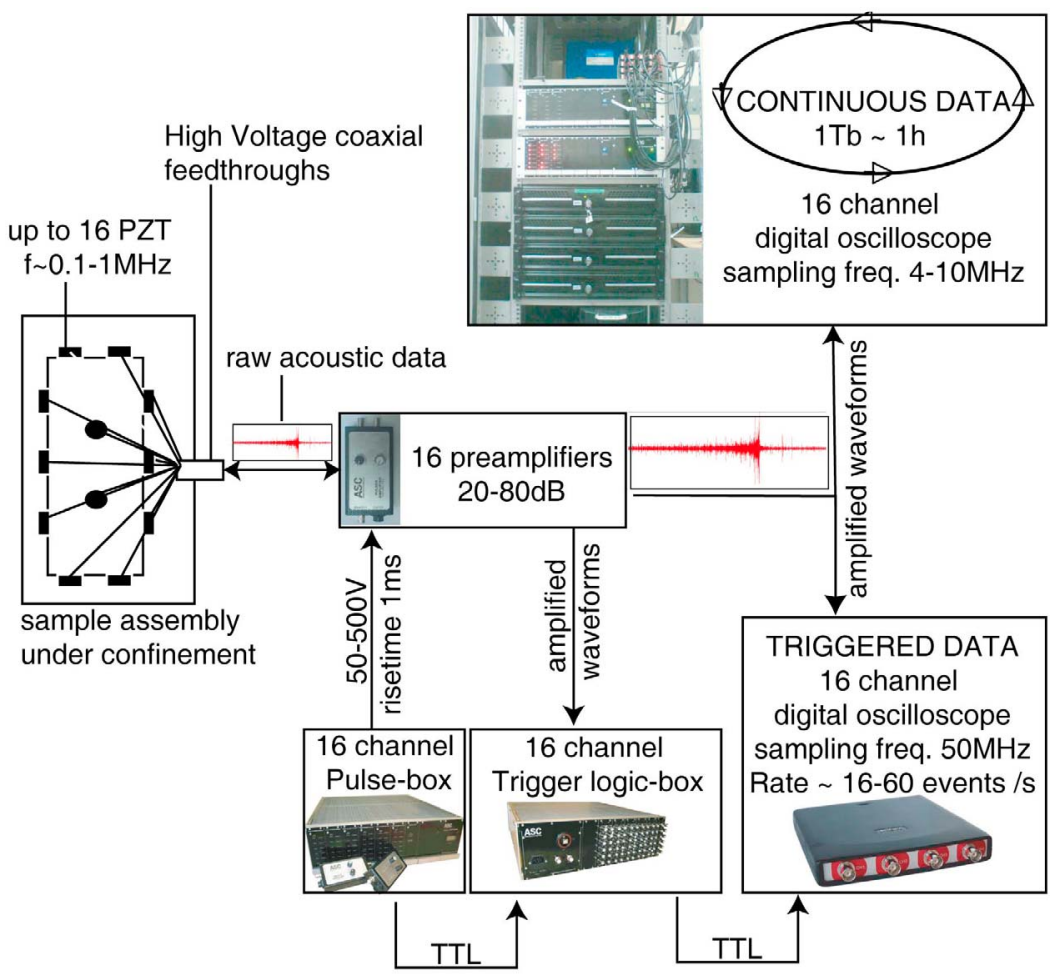

Figure 3. Schematic diagram of the AE recording system. Most of the signals were recorded twice, by the digital oscilloscopes (triggered data) and by the MiniRichter system (continuous data). All signals are amplified at $40 \mathrm{~dB}$ prior to recording.

with Ag-conductive epoxy to ensure a good mechanical coupling with the aluminium holder. At least one pair of horizontal $S$ wave PZTs was glued, in addition to the set of $P$ wave sensitive PZTs. The typical setup thus consists in $12 \mathrm{P}$ wave sensors and $2 \mathrm{SH}$ wave sensors glued onto the sample (Figure 1b). Once the sensors were glued, a soft glue was added around the PZTs onto the jacket to ensure sealing. Then the sample was placed inside the pressure vessel, in between two steel end plugs also equipped with $P$ and/or $S$ wave PZTs.

\subsection{Triaxial Apparatus}

[10] The deformation apparatus used for our experiments is an externally heated triaxial oil medium cell. Figure 2 shows a schematic view of this apparatus. The confining pressure is directly applied by a volumetric servopump up to a maximum of $100 \mathrm{MPa}$, and measured by a pressure tranducer with an accuracy of $10^{-3} \mathrm{MPa}$. The axial stress is controlled by an independent axial piston, actuated by a similar volumetric servopump. The axial stress is calculated from a pressure measurement at the inlet of the piston chamber and the surface ratio of the piston's ends. The maximum attainable axial stress on a $40 \mathrm{~mm}$ diameter sample is $\sim 680 \mathrm{MPa}$. A compressive shear stress is systematically ensured by applying an axial stress $\left(\sigma_{\text {axial }}\right)$ slightly higher than the confining pressure $\left(P_{\mathrm{c}}\right)$. In all tests, the minimum differential stress $\sigma_{\text {axial }}-P_{\mathrm{c}}$ thus ranges from $0.5 \mathrm{MPa}$ to $1.5 \mathrm{MPa}$.

[11] All the experiments were performed at controlled strain rates, which was achieved by adjusting the flow from the servopump connected to the axial piston. The initial strain rate in all tests is $\sim 10^{-5} \mathrm{~s}^{-1}$. During room temperature tests, it was repeatedly increased by a factor of 2 to test strain rate sensitivity of the samples' behavior. The axial deformation was measured externally using the average of three eddy current gap sensors fixed to the bottom end of the cell. In order to remove the contribution of the apparatus deformation in the total shortening, a calibration test was performed using an aluminium cylinder equipped with two pairs of strain gauges. An equivalent Young's modulus for the apparatus was calculated, yielding a value of $\sim 38 \mathrm{GPa}$. The total deformation recorded by the external measurement is thus corrected from this equivalent elastic deformation at a given differential stress.

[12] The heating system is external and consists of a silicone sleeve equipped with a heating wire wrapped around the pressure vessel. Due to the large volume of the cell, the maximum heating rate is $0.3^{\circ} \mathrm{C} \mathrm{min}^{-1}$ only, the advantage of this being that the temperature field is homogeneous in the sample. The temperature is recorded with two thermocouples, one plunged in the confining oil and one touching the bottom end of the lower steel plug. We consider that a constant homogeneous temperature is reached when the difference measured by the two thermocouples is less than $2^{\circ} \mathrm{C}$.

\subsection{Acoustic Emissions and Elastic Wave Velocity Measurements}

[13] The electric connection from the sensors inside the vessel to the outside is achieved by 16 high-voltage coaxial 
Table 1. Summary of All Tests Performed in This Study

\begin{tabular}{ccccccc}
\hline Test & $P_{\mathrm{c}}(\mathrm{MPa})$ & $T\left({ }^{\circ} \mathrm{C}\right)$ & Final Strain $(\%)$ & Peak/Yield Stress $(\mathrm{MPa})$ & First Stress Drop Occurrence $(\mathrm{MPa})$ & Hardening $(\mathrm{MPa})$ \\
\hline Vol04 & 10 & RT & 4.95 & 41.3 & 39.3 & - \\
Vol05 & 2 & RT & 3.48 & 19.8 & 72.8 & - \\
Vol06 & 95 & RT & 5.95 & $83 \pm 2$ & 52.6 & $4.7 \times 10^{2}$ \\
Vol07 & 20 & RT & 6.14 & $51 \pm 2$ & 63.8 & $0.45 \times 10^{2}$ \\
Vol08 & 50 & RT & 5.02 & $65 \pm 2$ & 29.2 & $-7 \times 10^{2}$ \\
Vol09 & 5 & RT & 5.30 & 29.6 & 41.0 & - \\
Vol10 & 95 & RT & 0.54 & - & 33.9 & - \\
Vol11 & 10 & RT & 6.56 & 36.55 & 67.7 & $6.1 \times 10^{2}$ \\
Vol13 & 10 & 70 & 1.25 & $66 \pm 2$ & 45.7 & $3.1 \times 10^{2}$ \\
Vol15 & 50 & 70 & 2.76 & $46 \pm 2$ & & - \\
Vol17 & 20 & 70 & 1.64 & & & \\
\hline
\end{tabular}

feedthroughs (Kemlon) that ensure a very low noise level. The coaxial wires are plugged into high-frequency $40 \mathrm{~dB}$ amplifiers with two distinct outputs. One output is continuously recorded at a $4 \mathrm{MHz}$ sampling rate by the Mini Richter System (ASC Ltd.), and the data are written on the fly onto four separate hard drives (recording four channels each). The second output goes through a trigger logic connected to digital oscilloscopes. If the signals verify a given pattern (e.g., a threshold amplitude on a given number of channels in a given time window), they are cut and recorded on the oscilloscopes at a $50 \mathrm{MHz}$ sampling rate. We will thus speak in terms of "streamed data" in the case of continuously recorded signals and "triggered data" in the other case. The main advantage of the streamed data is that it is possible to postprocess the full waveforms several times, and thus extract information that could be invisible on the triggered data (especially long-period waves [Thompson et al., 2005, 2006; Schubnel et al., 2006, 2007; Thompson et al., 2009]). This system is schematically summarized in Figure 3.

[14] In addition to passive AE recordings, active wave velocity surveys were performed. Repeatedly during the experiments, a strong, high-frequency $(1 \mu$ s risetime $)$ voltage of $200 \mathrm{~V}$ was pulsed on each channel while the other channels were recording. This results in the emission of a $P$ wave or $S$ wave (depending on the pulsing sensor), and since the origin time of the pulse and the sensor positions are known, the measurement of the travel times allows us to calculate the average velocity along each raypath. The data processing procedure is described in detail in section 3.3. According to our setup shown on Figure 1b, we have access at most to four different propagation angles of $P$ waves inside the sample: horizontal $\left(90^{\circ}\right)$, vertical $\left(0^{\circ}\right)$, a lowangle diagonal $\left(30.5^{\circ}\right)$, and a high-angle diagonal $\left(49.6^{\circ}\right)$. In addition, we measured horizontal $S H$ wave velocity and in some experiments horizontal $S V$ wave velocity. Such procedure allows us to distinguish anisotropy and macroscopic heterogeneities (of the order of the sensors spacing, i.e., approximately in centimeters). During active velocity surveys, it is not possible to record passively AEs.

\section{Stress-Strain Behavior and Elastic Wave Velocities}

\subsection{Mechanical Data}

[15] The experimental conditions for the series of 11 tests are shown on Table 1. All the samples were dry, and vented
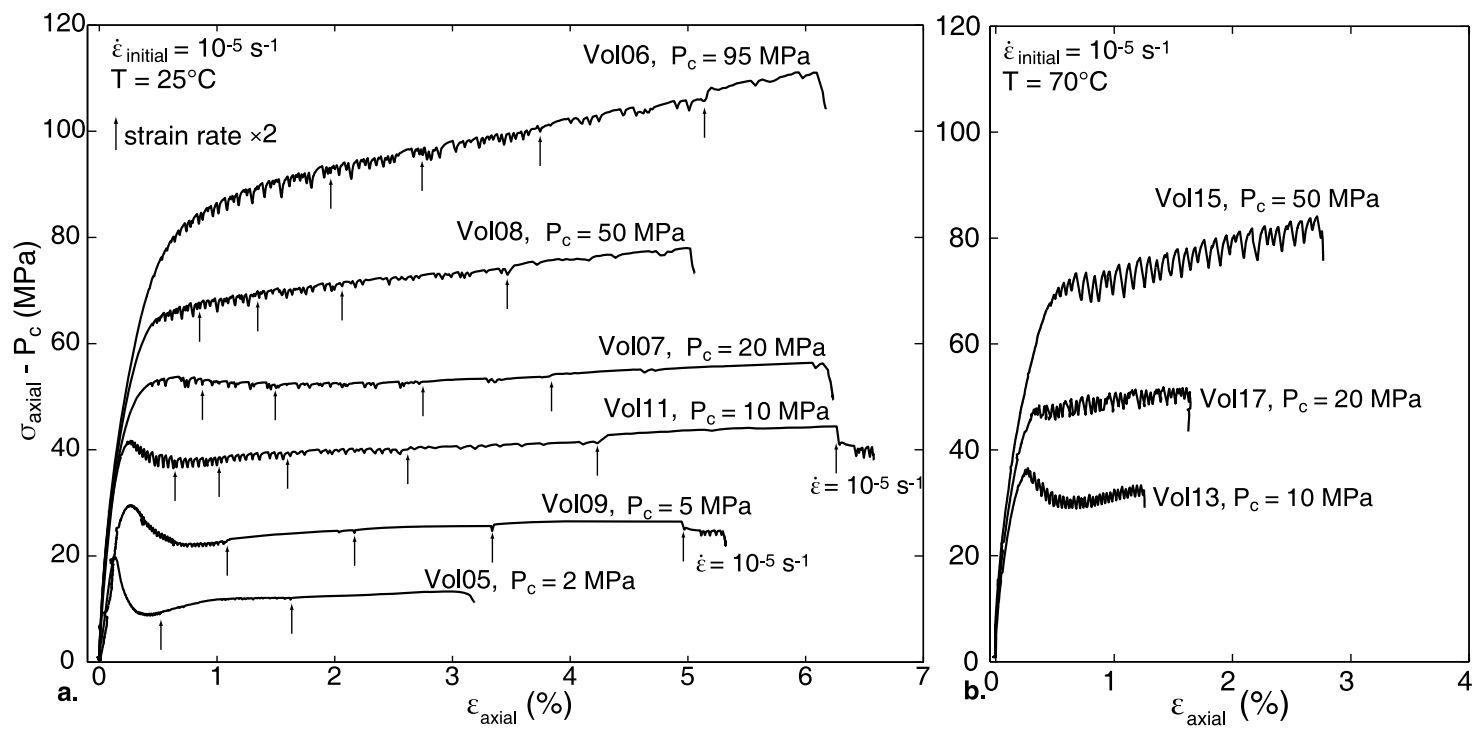

Figure 4. Stress-strain curves from deformation tests at (a) room temperature and (b) $70^{\circ} \mathrm{C}$. $\mathrm{Small}$ arrows indicate when strain rate was increased by a factor of 2 . 

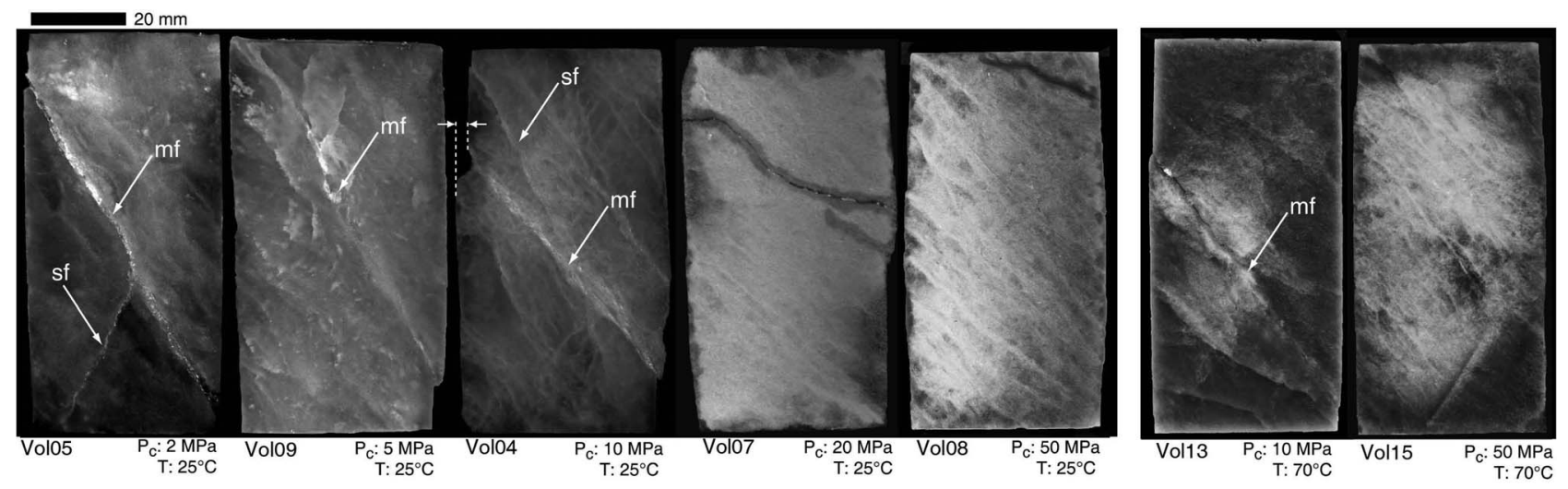

Figure 5. Macroscopic view of samples deformed at room temperature and $70^{\circ} \mathrm{C}$ after cutting. mf, main fracture; sf, secondary fracture. On the sample deformed at $P_{\mathrm{c}}=10 \mathrm{MPa}$, the sample remained cohesive and a significant displacement on the main fracture can be observed. Note the multiple shear bands in the samples deformed at high confining pressure.

to the atmosphere (drained). Figure 4 displays the stressstrain curves that are discussed in the following.

[16] At confining pressures up to $10 \mathrm{MPa}$, the samples deform in a strain-softening behavior. Beyond the peak stress, the differential stress starts to oscillate around a mean constant value; by increasing the strain rate, these stress oscillations can disappear. They can thus be considered as stick-slip events on a localized fault zone.

[17] At $P_{\mathrm{c}}=20 \mathrm{MPa}$ and room temperature, the stress level slightly decreases after the yield point until $3 \%$ axial strain, and then progressively increases. At $P_{\mathrm{c}}=20 \mathrm{MPa}$ and $70^{\circ} \mathrm{C}$, the behavior is globally strain hardening. At confining pressures above $20 \mathrm{MPa}$, the mechanical behavior is clearly strain hardening. Strain-hardening coefficients were estimated by fitting a straight line to postyield stress-strain curves (Table 1). The hardening coefficient increases with increasing $P_{\mathrm{c}}$ and temperature. Superimposed on this longterm behavior, numerous small stress drops can be observed. They do not disappear when the strain rate is increased. At room temperature and $P_{\mathrm{c}}=20 \mathrm{MPa}$, the amplitude of the stress drops ranges from a few bars up to $1.8 \mathrm{MPa}$. At $P_{\mathrm{c}}=$ $95 \mathrm{MPa}$, the biggest stress drop is around 3.5 $\mathrm{MPa}$. The amplitude of these events is quite scattered, but it seems that a higher confining pressure tends to induce larger events. At $70^{\circ} \mathrm{C}$, the average amplitude of stress drops is much larger: At $P_{\mathrm{c}}=20 \mathrm{MPa}$, the biggest one is already around $3.4 \mathrm{MPa}$.
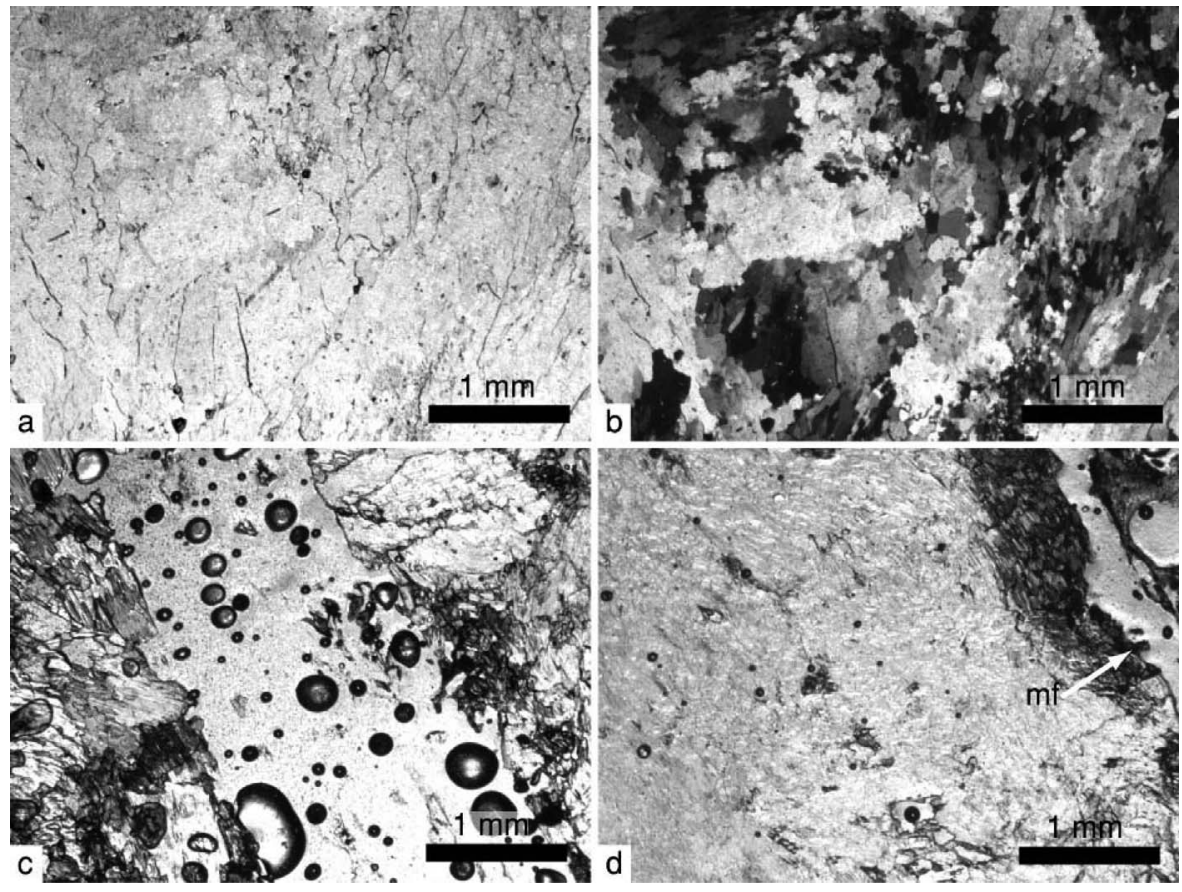

Figure 6. Optical micrographs of ( $a$ and b) the starting material and (c and d) the sample deformed at $P_{\mathrm{c}}=2 \mathrm{MPa}$ (Vol05). Observations were performed under transmitted light and uncrossed Nicols, except for Figure $6 \mathrm{~b}$; mf, main fracture. 


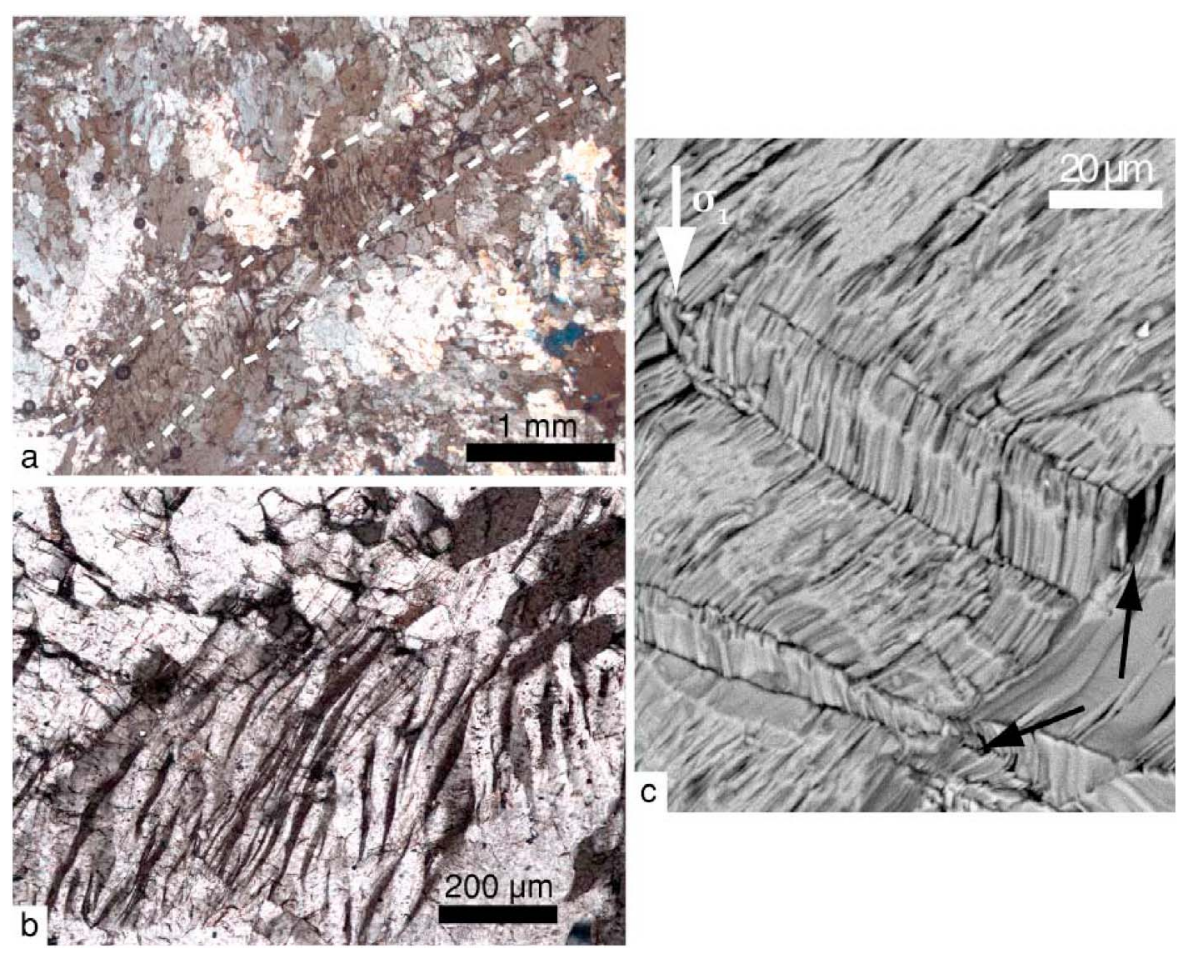

Figure 7. Optical micrographs of the sample deformed at $P_{\mathrm{c}}=20 \mathrm{MPa}$ (Vol07) (a and b) under transmitted light and crossed Nicols and (c) SEM picture of the sample deformed at $P_{\mathrm{c}}=50 \mathrm{MPa}$ (Vol08). Dotted lines (Figure 7a) delineate the approximate size of the shear band. Black stripes (Figure 7b) denote changes in crystal orientations. Arrows in Figure 7c indicate crack opening at the edges of the kinked grains.

In average, the axial displacement associated with a single stress drop event ranges from one to a few tens of microns.

\subsection{Microstructural Data}

[18] The macroscopic view of the deformed samples is shown in Figure 5. Up to $P_{\mathrm{c}}=10 \mathrm{MPa}$, the deformed samples display a major, incohesive fracture along with a few, smaller subfractures. At $2 \mathrm{MPa}$ and $5 \mathrm{MPa}$ confining pressure, the samples split and gouge was observed on the fracture surfaces. At $10 \mathrm{MPa}$ confining pressure, the sample remains cohesive, and a visual observation shows that the main fracture accommodated an important part of the deformation.

[19] Figure 6 shows optical microphotographs of thin sections prepared from an intact sample (Figures $6 \mathrm{a}$ and $6 \mathrm{~b}$ ) and a sample deformed at $P_{\mathrm{c}}=2 \mathrm{MPa}$ (Figures $6 \mathrm{c}$ and $6 \mathrm{~d}$ ). The main fracture can be observed in Figure 6c. Close to it, some areas contain microcracks. Far from the main fracture (over a few millimeters), the surrounding material remains almost intact. Similar observations hold for the samples deformed at $P_{\mathrm{c}}=5 \mathrm{MPa}$ and $P_{\mathrm{c}}=10 \mathrm{MPa}$.

[20] At $P_{\mathrm{c}}=20 \mathrm{MPa}$ and above, deformation is localized along multiple shear bands, and the samples remain cohesive (Figure 5). The shear bands consist in a localized mixture of crushed grains and kinked grains, and their thickness is around $500 \mu \mathrm{m}$ (Figure 7). The surface morphology of those shear bands was observed under a scanning electron microscope (SEM). A detailed observation of kinks suggests that there was microcrack opening during their formation, which is probably due to strain incompatibilities at the edges of the kinked grains (Figure 7c).
[21] The shear bands that appear at elevated confining pressure are thus a combination of brittle (microcracks) and plastic (kinks) processes. The "ductile" deformation of gypsum at those conditions is thus a "semibrittle" deformation.

[22] An additional test was performed at $P_{\mathrm{c}}=95 \mathrm{MPa}$ during which the deformation was stopped after a finite, countable number of stress drops (Figure 8a). The sample was then cut and we visually estimated the number of shear bands (Figure $8 \mathrm{~b}$ ), which approximately corresponds to the number of stress drops. This suggests that shear banding at high $P_{\mathrm{c}}$ induces a stress drop.

\subsection{Elastic Wave Velocity Data}

[23] Using the set of sensors described in section 2, elastic wave velocities are measured repeatedly during the tests. Using 16 sensors produces a set of $15 \times 16$ waveforms. The origin time $t_{0}$ is recorded and thus known. $P$ wave arrival times are automatically picked using the Insite software (ASC Ltd.); $S$ waves are manually picked by the user. A reference survey, generally performed at the highest hydrostatic pressure experienced by the sample, is then chosen. This "master" survey is processed using the known positions of sensors and picked arrival times to yield an absolute value of the wave velocities. All waveforms are then cut around the picking time in a $5 \mu$ s window and cross correlated with the master survey, and the position of the maximum of the cross-correlation coefficient gives the shift in $P$ or $S$ wave arrival time. This method provides an automatic measurement of the relative $P$ and $S$ wave 


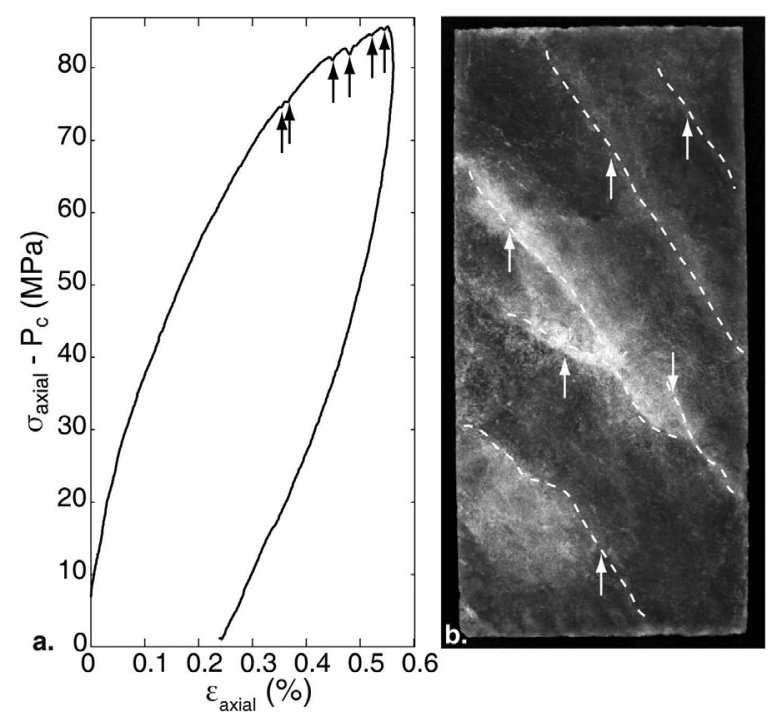

Figure 8. (a) Stress-strain curve and (b) photograph from a test at $P_{\mathrm{c}}=95 \mathrm{MPa}(\mathrm{Vol10})$. Deformation was stopped after the occurrence of six stress drops. Figure $8 \mathrm{~b}$ shows the presence of five to six distinct shear bands, suggesting that each stress drop is associated with an individual shear band.

velocity evolution during the tests. It cancels the intrinsic errors of manual or automatic picking processes. However, the absolute value may be slightly shifted due to these types of errors in the picking of the master survey.

[24] As mentioned in section 2, the set of active velocity surveys provides measurements at four angles inside the sample. For the sake of simplicity we assume at first that the samples are homogeneous, and thus we present here the average of the elastic wave velocities along each raypath.

[25] Figure 9 is a plot of the $P$ and $S$ wave velocities as a function of mean stress during a hydrostatic loading path up to $98 \mathrm{MPa}$. The $P$ wave velocities increase gradually as loading increases. This increase is the same in all directions of propagations, and is quite small: around $100 \mathrm{~m} \mathrm{~s}^{-1}$. The $\mathrm{SH}$ wave velocity is roughly constant. These data indicate that very few preexisting cracks or defects are present in the sample.

[26] Figure 10 is a summary plot of the $P$ and $S$ wave velocity evolution during deformation for the tests performed at elevated confining pressure. $P$ and $S$ wave velocities decrease continuously with increasing axial deformation. The velocities measured at low angle, i.e., close to the loading direction, decrease less than those measured at high angle. An elastic anisotropy is thus developing during deformation. This anisotropy seems to decrease with increasing $P_{\mathrm{c}}$ and temperature.

[27] At $P_{\mathrm{c}}=20 \mathrm{MPa}$ and $T=25^{\circ} \mathrm{C}$, the horizontal $P$ wave velocity decreases from $5250 \mathrm{~m} \mathrm{~s}^{-1}$ down to $3000 \mathrm{~m} \mathrm{~s}^{-1}$ at $6.2 \%$ axial deformation. It corresponds to $43 \%$ decrease. Likewise, horizontal $\mathrm{SH}$ wave velocity decreases by $28 \%$. At $P_{\mathrm{c}}=95 \mathrm{MPa}$ the horizontal $P$ wave velocity decreases by $20 \%$ and the $S H$ wave velocity decreases by $20 \%$ at $6.2 \%$ axial deformation. The decrease in $P$ wave velocity is thus less at high confining pressure than at low confining pressure.
[28] Compared to experiments performed at room temperature, those performed at $70^{\circ} \mathrm{C}$ induce smaller changes in $P$ and $S$ wave velocities. For instance, at $P_{\mathrm{c}}=20 \mathrm{MPa}$ and $T=70^{\circ} \mathrm{C}$ the variation in horizontal $P$ wave velocity is only $-14 \%$ for an axial deformation of $1 \%$. For the room temperature test, this change is $-19 \%$ for the same amount of axial deformation. Such observations are consistently reproduced for all measurements when we compare samples that reached the same amount of deformation.

\section{Acoustic Emissions}

\subsection{Room Temperature Experiments}

[29] Using our acoustic monitoring system it was possible to record a significant number of distinct AEs during most of the tests. Let us first focus on the low confining pressure rupture experiments, at $P_{\mathrm{c}}=2 \mathrm{MPa}$ and $P_{\mathrm{c}}=5 \mathrm{MPa}$.

[30] For a given AE, we manually pick the first wave arrival on the signal recorded on each channel. Only $P$ wave transducers are used for this procedure. Depending on the quality of the sensor and on the amplitude of the source, some channels may be unusable. If the number of available arrival times is more than six, the AE can be located. The location procedure is the following. First we compute the average $P$ wave velocity measured by the active surveys as described in section 3. A homogeneous, transversely isotropic model of the velocity field is used. Assuming weak anisotropy, we approximate the variation of the $P$ wave velocity $V$ with the propagation angle $\phi$ (defined relatively to the axis of symmetry) by the following relation [Thomsen, 1986]:

$$
V=\left(\frac{V_{\mid}+V_{\perp}}{2}\right)-\left(\frac{V_{\perp}-V_{\perp}}{2}\right) \cos (\pi-2 \phi),
$$

where $V_{\mid}$is the velocity parallel to the symmetry axis, and $V_{\perp}=a V_{\mid}$is the velocity perpendicular to it. This defines $a$ as

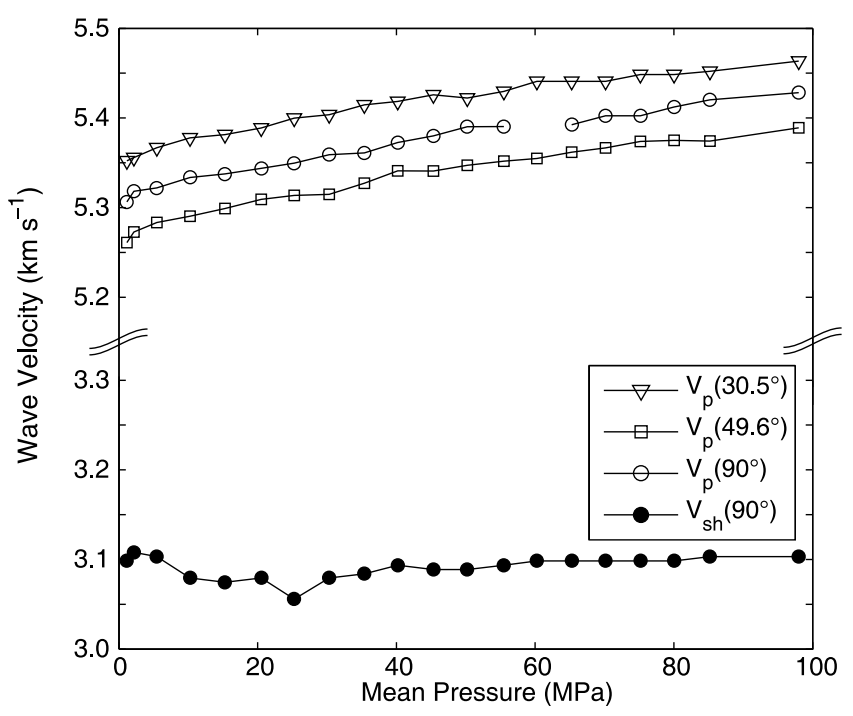

Figure 9. Elastic wave velocity evolution during hydrostatic loading (Vol06). $P$ wave velocity increases similarly in all directions of propagation. $S$ wave velocity is approximately constant. 

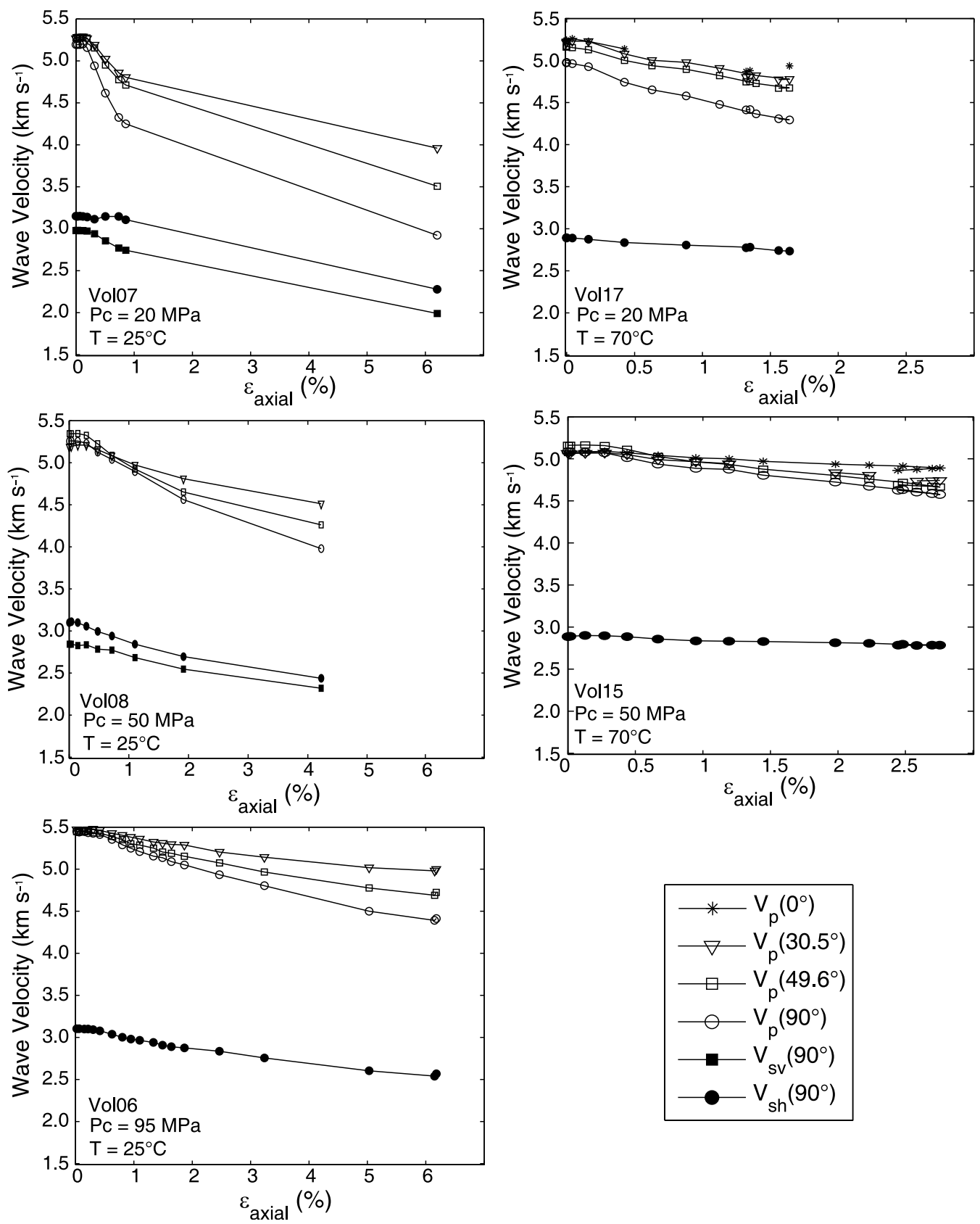

Figure 10. Elastic wave velocity evolution during deformation tests. The corresponding experimental conditions are reported on each graph. All types of elastic waves decrease significantly with increasing deformation.

an anisotropy index. Then the inverse problem of the $\mathrm{AE}$ location is solved by a 3-D collapsing grid-search algorithm that minimizes the absolute value of the difference between theoretical and measured arrival times. The minimum grid spacing at the third iteration is around $1 \mathrm{~mm}$, which is a good resolution for an AE location without considering the errors in sensor locations and sensor size. This method uses a least absolute values criterion and is thus robust to aberrant data.

[31] The main error source in $\mathrm{AE}$ locations comes from the simplified, homogeneous velocity model we adopt. For a given set of velocity and anisotropy index values, we esti- mate the error by relocating the sensor positions, using arrival time data from an active velocity survey.

[32] During experiment Vol05, performed at $P_{\mathrm{c}}=2 \mathrm{MPa}$, a total number of 232 prerupture events were recorded. Among those, 211 events can be localized inside the sample. We used a transversely isotropic model for $P$ waves with a maximum vertical $P$ wave velocity of $V_{l}=5150 \mathrm{~m} \mathrm{~s}^{-1}$ and an anisotropy index of $a=0.975$. The corresponding average location error is $\pm 2.3 \mathrm{~mm}$. The located events are displayed on Figures 11a and $11 \mathrm{~b}$ on a map projection along with the picture of the sample after cutting. At the beginning of the test, for $\sigma_{\text {axial }}-P_{\mathrm{c}}<10.8 \mathrm{MPa}$, the located events 


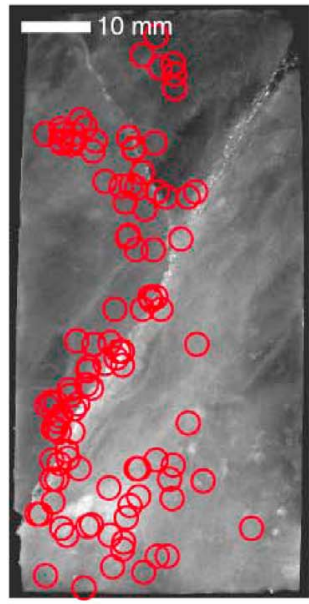

a. $\mathrm{P}=2 \mathrm{MPa}, \mathrm{T}=25^{\circ} \mathrm{C}$ $0.5<\sigma_{a x i a \mid}-P_{c}<10.8 \mathrm{MPa}$

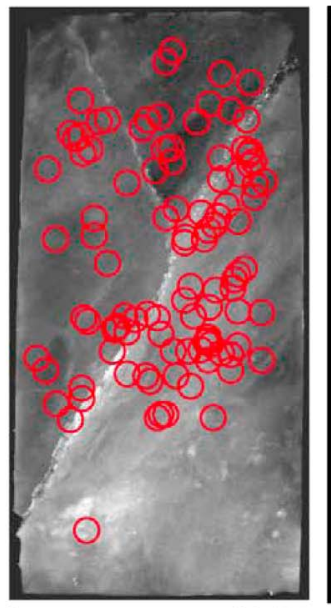

Vol05 c. $\mathrm{P}_{\mathrm{C}}=2 \mathrm{MPa}, \mathrm{T}=25^{\circ} \mathrm{C}$ $10.8<\sigma_{a x i a \mid}-P_{c}<19.5 \mathrm{MPa}$

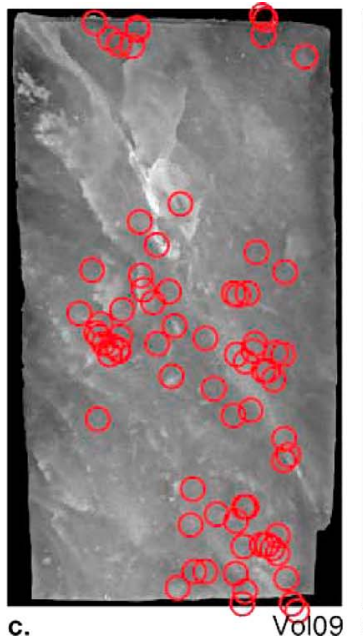

$\mathrm{P}_{c}=5 \mathrm{MPa}, \mathrm{T}=25^{\circ} \mathrm{C}$ $0.4<\sigma_{\text {axial }}-P_{c}<19.1 \mathrm{MPa}$

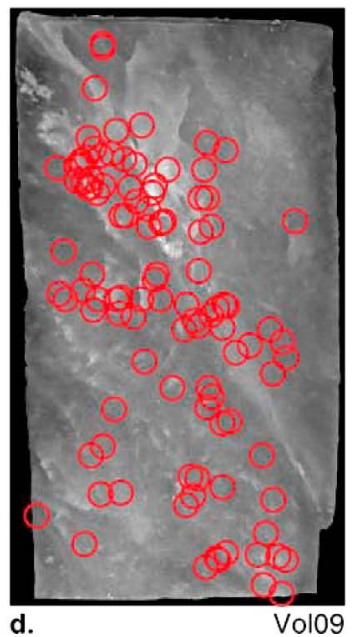

$\mathrm{P}_{\mathrm{C}}=5 \mathrm{MPa}, \mathrm{T}=25^{\circ} \mathrm{C}$

$19.1<\sigma_{\text {axial }}-P_{c}<27.9 \mathrm{MPa}$

Figure 11. Projection of AE locations for the tests performed at $P_{\mathrm{c}}=2 \mathrm{MPa}$ and $P_{\mathrm{c}}=5 \mathrm{MPa}$ on the cutting plane. The circle size corresponds to the average location error. (a and b) Test performed at $P_{\mathrm{c}}=2 \mathrm{MPa}$. A total of 211 AEs are shown. (c and d) Test performed at $P_{\mathrm{c}}=5 \mathrm{MPa}$. A total of 210 AEs are shown. The locations are scattered but are generally correlated to the presence of the fracture plane.

align roughly along the main and secondary fractures. At higher differential stress the events become more scattered. Similarly, Figures 11c and 11d show the 210 events out of 214 that could be localized during experiment Vol09 $\left(P_{\mathrm{c}}=\right.$ $5 \mathrm{MPa}$ ). For this test we used a homogeneous model for $P$ waves with a $P$ wave velocity of $5300 \mathrm{~m} \mathrm{~s}^{-1}$; the corresponding average error is $\pm 2.4 \mathrm{~mm}$. The AEs are scattered at all stages of the test, and even a general trend is hard to distinguish.

[33] At higher confining pressure or temperature, fewer AEs were recorded prior to yielding, even in tests Vol04 and Vol11 performed at $P_{\mathrm{c}}=10 \mathrm{MPa}$. AEs were hard to locate because they have nonimpulsive risetimes and low amplitude. However, the continuous recording system enabled us to investigate the global acoustic activity during all the tests. It provides an interesting qualitative tool to estimate the amount of dynamic microcracking during deformation. Figure 12 presents the continuous waveform recorded on a sensor located at midheight on the sample surface (either P3W, P3S, P3E, or P3N; compare Figure 1b) for all the tests performed at room temperature. The blanks correspond to the time intervals when active surveys are performed. Despite the likely variations of the amplitude response of the sensors and noise, such comparison gives a rough idea of the acoustic activity changes with varying confining pressure. In Figure 12, an AE corresponds to a short spike in the waveform: Its duration is usually a few tens of microseconds, i.e., $\sim 10^{8}$ times shorter than the duration of the experiment itself. In all cases, the maximum AE count and amplitude are reached slightly before the yield point. The stress drops are only scarcely correlated with particular bursts of $\mathrm{AE}$. The $\mathrm{AE}$ count and $\mathrm{AE}$ amplitudes are much higher at low pressure than at high pressure, which suggests that the microcracking processes radiate more elastic energy at low pressure than at high pressure.

\section{2. $70^{\circ} \mathrm{C}$ Experiments}

[34] The experiments performed at $70^{\circ} \mathrm{C}$ are processed similarly. Figure 13 is a plot of continuous waveforms recorded on one sensor, superimposed to the differential stress as a function of time. The first occurrence of AEs starts slightly before the yield point. The major difference with room temperature tests is that large-amplitude, lowfrequency $\mathrm{AE}$ signals are recorded simultaneously with every stress drop. The frequency of these events is actually low enough to be heard by the human ear. Such signals were never recorded during the tests performed at room temperature.

[35] At this point an important distinction needs to be made between what we will call in the following a "regular $A E$ " and a "low-frequency AE" (LFAE). Figure 14 summarizes the variety of signals recorded during a deformation test at $70^{\circ} \mathrm{C}$ and $P_{\mathrm{c}}=50 \mathrm{MPa}$ (vol15), as well as their power spectral densities. Figures $14 \mathrm{a}$ and $14 \mathrm{~b}$ correspond to a regular $\mathrm{AE}$, which can be defined by a short duration, of the order of $10 \mu \mathrm{s}$, and a dominant high-frequency content (significant frequency peaks are over $100 \mathrm{kHz}$ ); they do not correspond to a macroscopic stress drop. Representative examples of LFAEs recorded during stress drop events are displayed on Figures $14 \mathrm{c}-14 \mathrm{~h}$. Their duration is of the order of a few milliseconds, and their frequency content is dominated by a peak at $\sim 8.8 \mathrm{kHz}$; as opposed to regular AEs, they systematically accompany the macroscopic stress drops recorded during deformation. The intensity and duration of the LFAEs, as represented in Figures $14 \mathrm{c}, 14 \mathrm{e}$, and 14g, are variable from one event to another.

[36] Some LFAEs, as shown in Figure 14c, have a relatively long duration and do not present any sharp peak in amplitude; they occur as swarms of AE activity. On the other hand, some LFAEs (Figure 14g) are significantly shorter and contain distinct amplitude peaks at relatively 


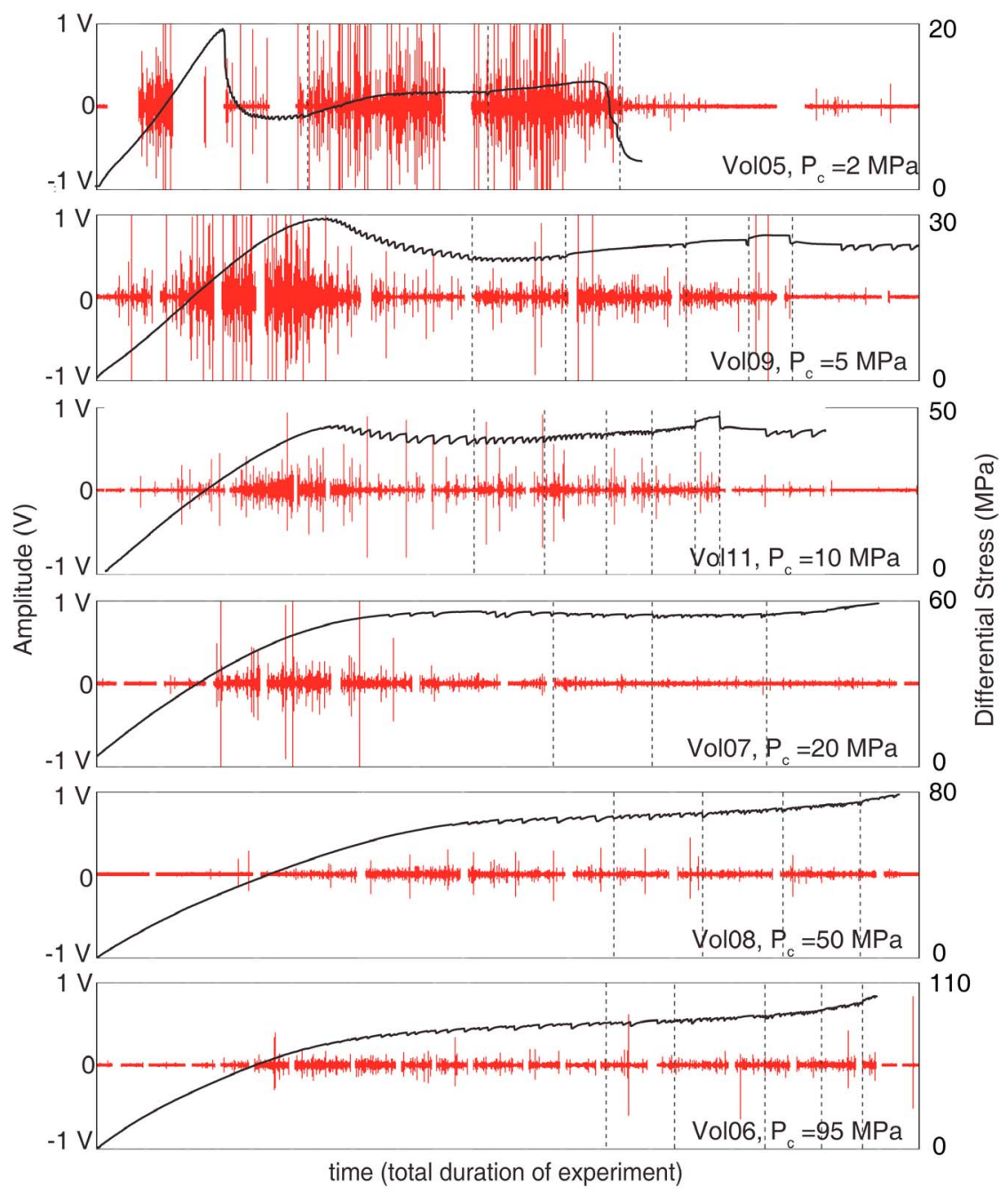

Figure 12. Stress-time curve and continuous waveforms recorded on a central sensor for room temperature experiments. Each sensor shown here is located at midheight on the sample surface (either P3W, P3S, P3E, or P3N; compare Figure 1b). Blanks correspond to the time when active surveys are performed. Dotted lines correspond to the time when the strain rate is increased by a factor of 2 , as denoted on Figure 4.

low frequency. Intermediate events also occur, as shown in Figure 14e. In the example event displayed in Figure 14g, at least two phases can be distinguished. The event starts as a swarm (phase I), in a very similar way as the other types of LFAEs, but a major peak in amplitude occurs (phase II) and then the signal decreases in long-period oscillations.

\section{Interpretations and Discussion}

\subsection{Micromechanics of Deformation}

[37] The mechanical behavior of the samples tested at $70^{\circ} \mathrm{C}$ do not fundamentally differ from those tested at room temperature. In Figure 15 we report the occurrence of the first stress drop and yield stress as a function of mean stress and differential stress. The series of points defines a boundary above which the mechanical behavior changes dramatically. This boundary is certainly not the elastic limit of the samples, since there is a clear nonlinearity of the stress-strain curves even before the first stress drop; however, this is a convenient and reproducible way to denote the change in the mechanical behavior. The boundary at room temperature does not significantly differ from that at $70^{\circ} \mathrm{C}$; it is thus probable that the microprocesses involved in this change of behavior are the same.

[38] $P$ and $S$ wave velocities continuously decrease during deformation, which suggests that microcracks are forming. They can be related to the strain incompatibilities at the edges of kinked grains, as well as cleavage plane or grain boundary opening. Assuming an initially homogeneous, isotropic medium, it is possible to quantitatively interpret the velocity data using an effective medium theory. We are in particular interested in comparing relative measurements. We thus use the noninteractive approach as described by Sayers and Kachanov [1995]. The advantage of this model is that it allows a transversely isotropic orientation distribution of cracks, and can explain the development of $P$ 


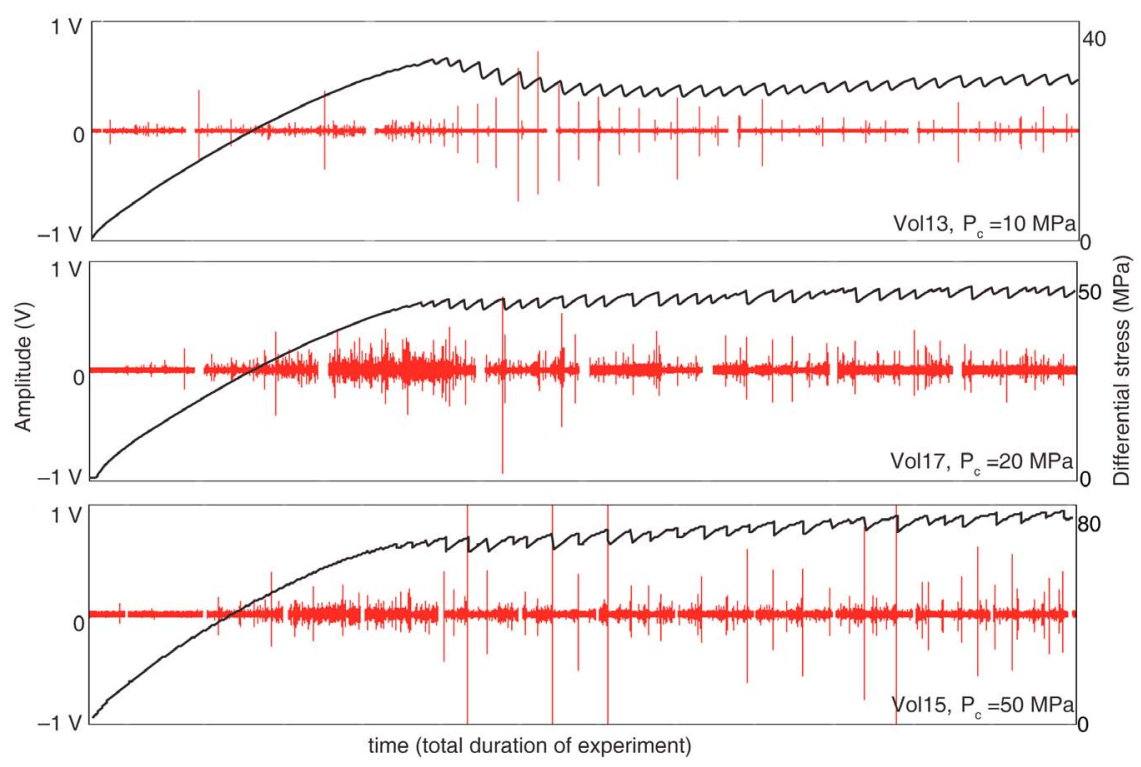

Figure 13. Stress-time curve and continuous waveforms recorded on a central sensor for $70^{\circ} \mathrm{C}$ tests. Each sensor shown here is located at midheight on the sample surface (either P3W, P3S, P3E, or P3N; compare Figure 1b). Blanks correspond to the time when active surveys are performed.

wave anisotropy in an initially isotropic medium. The inversion process allows one to retrieve equivalent vertical and horizontal crack densities (see Appendix A). This separation of crack density in two principal orientations actually corresponds to the decomposition of cracks with any orientations into equivalent orthogonal cracks. The results are plotted on Figure 16. Below 1\% axial deformation, the vertical $\left(\alpha_{11}=\alpha_{22}\right)$ and horizontal $\left(\alpha_{33}\right)$ crack densities are of the same order of magnitude. When the sample is further deformed, the vertical crack density becomes much higher than the horizontal crack density. This can be understood as the formation of not purely vertical cracks that can be decomposed into a large component along the vertical axis of compression (high $\alpha_{11}=\alpha_{22}$ ), and a small component along the horizontal axis (low $\alpha_{33}$ ). This corresponds to the development of the crack-induced anisotropy that we observed on the raw velocity data. The crack density is systematically lower at high confining pressure than at low confining pressure. Likewise, at $70^{\circ} \mathrm{C}$ the crack density is significantly lower than at room temperature. The damage almost linearly increases with increasing axial strain: Microcracks accumulate as shear bands are formed, but the sample keeps its integrity. To our knowledge, our data set is the first to show such a linear relationship between crack density and deformation; typically, brittle rocks accumulate microcracks nonlinearly prior to localization [Schubnel et al., 2003; Fortin et al., 2006].

[39] As shown in Figure 16, at a given finite strain the samples deformed at $70^{\circ} \mathrm{C}$ have a lower crack density than the samples deformed at room temperature. If the total inelastic strain is written as the sum of the contribution from cracks, and from plastic processes, i.e.,

$$
\epsilon_{\text {inelastic }}=\epsilon_{\text {plastic }}+\epsilon_{\text {cracks }}
$$

it implies that the ratio $\epsilon_{\text {plastic }} / \epsilon_{\text {cracks }}$ is higher at elevated temperature than at room temperature. This is consistent with the fact that plastic processes are usually thermally activated, as they involve dislocation motion and/or diffusion phenomena. As shown by the microstructural observations, the main plastic process involved in gypsum deformation during the tests seems to be grain kinking.

[40] A particular feature of grain kinking is its dependency on crystal orientation with respect to the stress orientation. Gypsum is a crystal salt that includes a large amount of water in its structure. The water molecules lie along the (010) planes, and thus only hydrogen bonds hold the structure along these planes that are perfect cleavage planes. This allows the mineral to kink when the maximum principal stress is aligned with this plane [Turner and Weiss, 1965]. Such a feature may help one to understand the formation of shear bands at elevated confining pressure.

[41] At $P_{\mathrm{c}} \geq 20 \mathrm{MPa}$, the deformation is localized within bands of finite thickness $(\sim 500 \mu \mathrm{m})$ containing microcracks and kinked grains, associated with stress drops of finite amplitudes and durations. In between those stress drop events, a significant AE activity is recorded (see Figures 12 and 13). Microcracking is thus occurring during the reloading phase after a stress drop, probably along with progressive grain kinking. It is thus possible that microcracks accumulate throughout the sample during the reloading phase, until kinking starts to operate on one or several grains that are favorably oriented. The kinked grains may act as soft inclusions that induce strain incompatibilities around them, and could be the initiation points of the shear bands.

[42] At elevated confining pressure, numerous shear bands are observed, which indicates that a shear band is not easily reactivated after its formation. This suggests a saturation process, i.e., a hardening of the shear band after it accommodates a finite amount of strain. How does this process operate? Geometrically, a single gypsum grain cannot accommodate an infinite amount of deformation by kinking. There must be a hardening process at the grain scale, i.e., a critical kink angle at which other mechanisms 

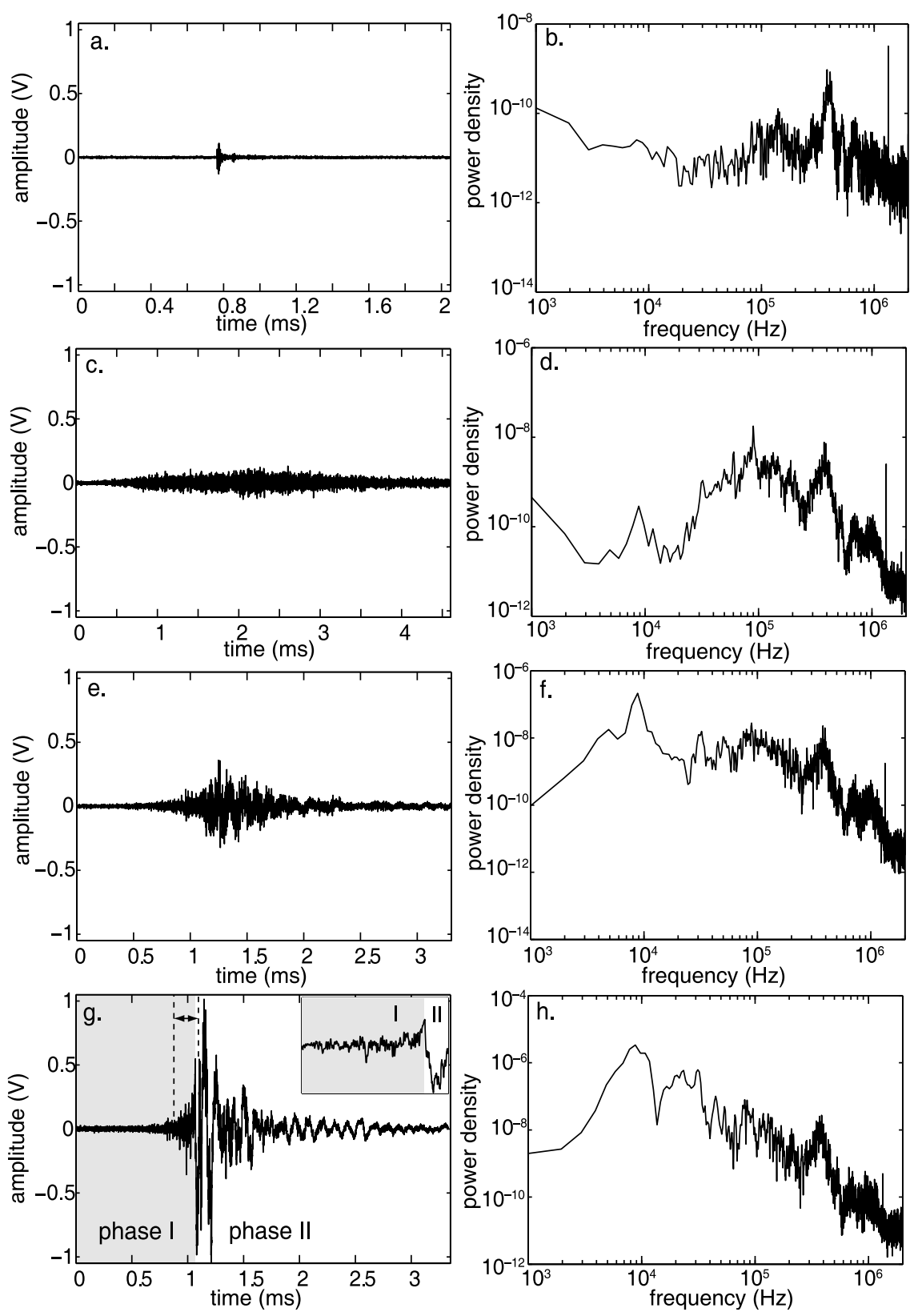

Figure 14. Typical waveforms and power density spectra (a and b) of a regular AE and (c-h) of various LFAEs recorded during stress drops at $70^{\circ} \mathrm{C}$. Note the difference in timescales. The power density spectra of all LFAEs contain a peak at $8.8 \mathrm{kHz}$. The event shown in Figure 14g seems to occur in two phases (I and II) and the inset corresponds to a zoom in the time interval denoted by the dotted lines.

have to be involved to further deform the grain. Our experiments suggest that grain kinking is a major deformation mode during shear band formation. It is likely that after a certain amount of deformation the energy needed to further deform the grains becomes larger than the energy needed to form a new shear band. In this framework, each band may correspond to a finite strain, and the total strain may be the sum of the contributions of all the shear bands.

[43] At $70^{\circ} \mathrm{C}$, plasticity (i.e., kinking) contributes to a larger extent to the total inelastic deformation. The saturation process of grain kinking at the grain scale may thus explain why the long-term hardening is larger at $70^{\circ} \mathrm{C}$ than at room temperature. Moreover, if the shear bands are viewed as a cascade of kinks (accompanied by microcracks), a higher background temperature may promote larger stress drops, consistent with the observations shown in Figure 4.

\subsection{Rupture Dynamics}

[44] At $70^{\circ} \mathrm{C}$ and elevated confining pressure, the shear band formation induces a large, dynamic stress drop that we record with AE sensors. The LFAE signals can be processed to explore the details of the dynamics of deformation.

[45] As seen in Figures 14d, 14f, and 14h, the LFAEs have significant frequency components in the range 1- 


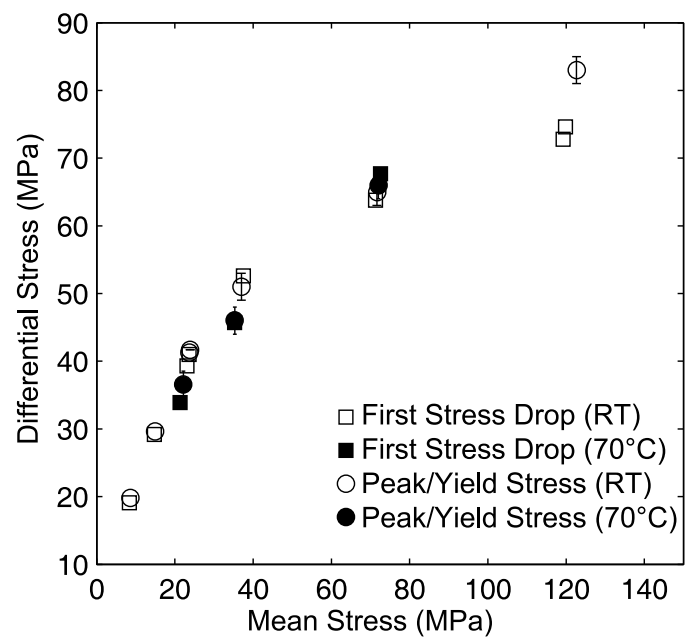

Figure 15. Onset of the first stress drop and yield stress in the mean and differential stress plane.

$100 \mathrm{kHz}$. Within this frequency range, a component at $8.8 \mathrm{kHz}$ is systematically observed. This particular peak might correspond to a resonant frequency of the sample assembly and/or its surrounding confining medium (the wavelength associated with this component is $\sim 50 \mathrm{~cm}$ for a wave velocity of $\sim 5 \mathrm{~km} \mathrm{~s}^{-1}$, or of the order of $17 \mathrm{~cm}$ if the wave speed is that of the confining oil). At $70^{\circ} \mathrm{C}$, the rupture process is thus rapid and powerful enough to induce oscillations of the whole medium, which is not seen (at least within the sensitivity range of our sensors) during the stress drop events at room temperature.

[46] The low-frequency waveforms can be processed in order to remove the low-frequency content that might not be strictly related to the source processes. A high-pass Butterworth filter of order 1, with a low-frequency cutoff at $500 \mathrm{kHz}$ is applied. The resulting signal, presented in Figure 17 (middle), still displays a significant amplitude.

[47] The high-frequency part of the LFAEs may originate from microcrack propagation during the stress drop events. In that case, the duration of each event can be estimated by measuring the duration of the high-frequency signals within the LFAE. Starting from the filtered signals $S_{i}^{\mathrm{HF}}(t)$ (where $i$ corresponds to the channel number), we calculate the integral $\Sigma_{i}(t)$ defined by

$$
\Sigma_{i}(t)=\int_{0}^{t}\left(S_{i}\left(t^{\prime}\right)^{\mathrm{HF}}\right)^{2} d t^{\prime}
$$

For each signal $\Sigma_{i}(t)$, the baseline corresponding to integrated noise is removed by subtracting a linear fit to the first 500 points of $\Sigma_{i}(t)$. The subsequent signal is then normalized, and sigmoid curves ranging from 0 to 1 are obtained (cf. gray curves in Figure 17, bottom). In order to avoid local effects the average of those curves over all channels $i$ is calculated (black curve in Figure 17, bottom). The risetime $t_{\text {rupture }}$ of the mean curve is calculated as the time for the mean normalized signal to increase from 0.1 to 0.9 . Such a definition implies that $80 \%$ of the high-frequency energy of the waves is released during $t_{\text {rupture. It can thus be seen as }}$ a good upper-bound estimate of the rupture duration. In all experiments, the rupture time defined as above ranges from
0.3 to $1 \mathrm{~ms}$. Considering a maximum rupture length of $\sim 5 \mathrm{~cm}$, such rupture durations correspond to average rupture velocities of the order of $50 \mathrm{~m} \mathrm{~s}^{-1}$ to $200 \mathrm{~m} \mathrm{~s}^{-1}$. Because we calculate an upper bound for the rupture duration, these values correspond to lower bound of the rupture speed.

[48] From the rupture duration and the axial shortening measurement, we can now estimate the average slip rate during a stress drop event. Using a displacement of the order of $20 \mu \mathrm{m}$ over a duration of the order of $0.5 \mathrm{~ms}$, we obtain a slip rate of the order of $4 \mathrm{~cm} \mathrm{~s}^{-1}$. This value is relatively high, and could possibly induce a significant shear heating within the band. The shear band thickness is approximately $500 \mu \mathrm{m}$, so the strain rate is $\dot{\gamma} \approx 80 \mathrm{~s}^{-1}$. The shear stress acting on a band is of the order of $0.5\left(\sigma_{\text {axial }}-P_{\mathrm{c}}\right)$, that is, $\tau \approx$ $30 \mathrm{MPa}$ (for a test at $P_{\mathrm{c}}=50 \mathrm{MPa}$ ). Thus, the shear energy per unit volume is of the order of $\tau \dot{\gamma} \approx 2.410^{9} \mathrm{~J} \mathrm{~m}^{-3} \mathrm{~s}^{-1}$. The heat capacity $C$ of gypsum is $1.110^{3} \mathrm{~J} \mathrm{~kg}^{-1} \mathrm{~K}^{-1}$, and the density of gypsum is $d=2.310^{3} \mathrm{~kg} \mathrm{~m}^{-3}$. Assuming adiabatic conditions, the average heating rate within the band is $\tau \dot{\gamma} /(d C) \approx 1000 \mathrm{~K} \mathrm{~s}^{-1}$. The duration of slip being of the order of $0.5 \mathrm{~ms}$, the temperature increase is thus only $0.5 \mathrm{~K}$. This
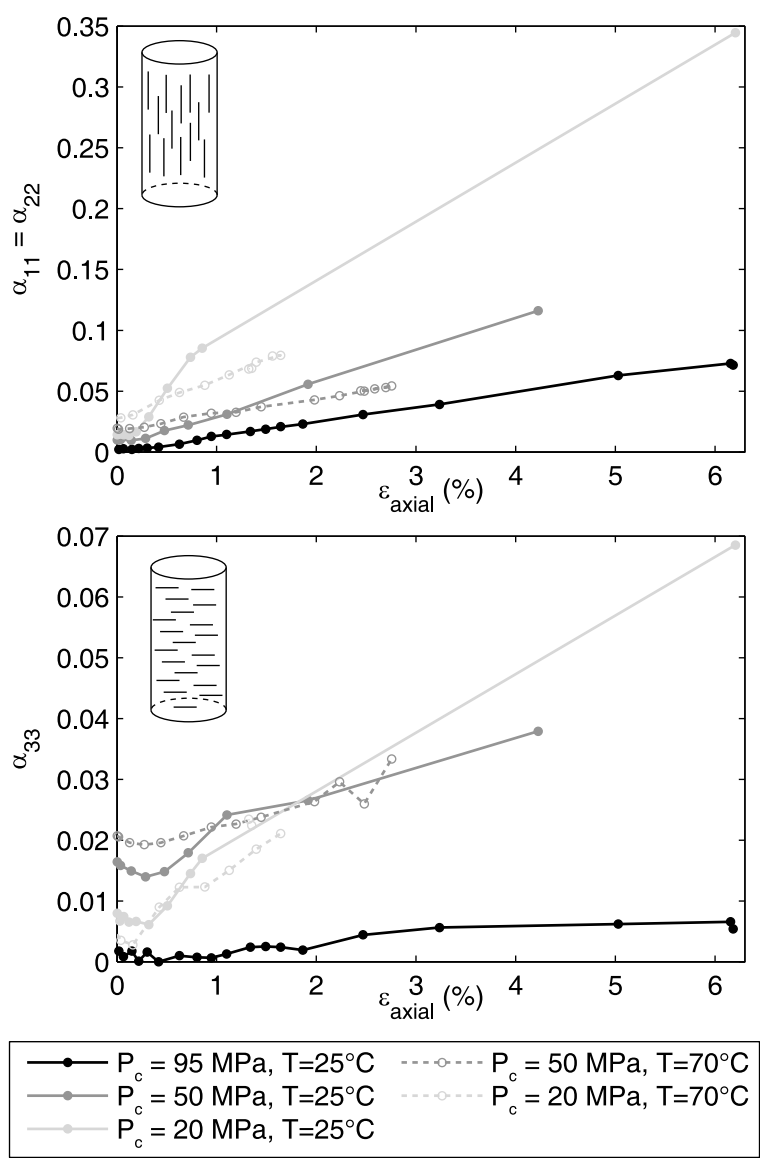

Figure 16. Evolution of vertical crack density $\alpha_{11}$ and horizontal crack density $\alpha_{33}$ during high $P_{\mathrm{c}}$ tests. Note the different vertical scales. The inversion process is fully described in Appendix A. Crack density increases regularly with increasing axial strain. The rate of increase is higher at low confining pressure, and for low-temperature tests. 

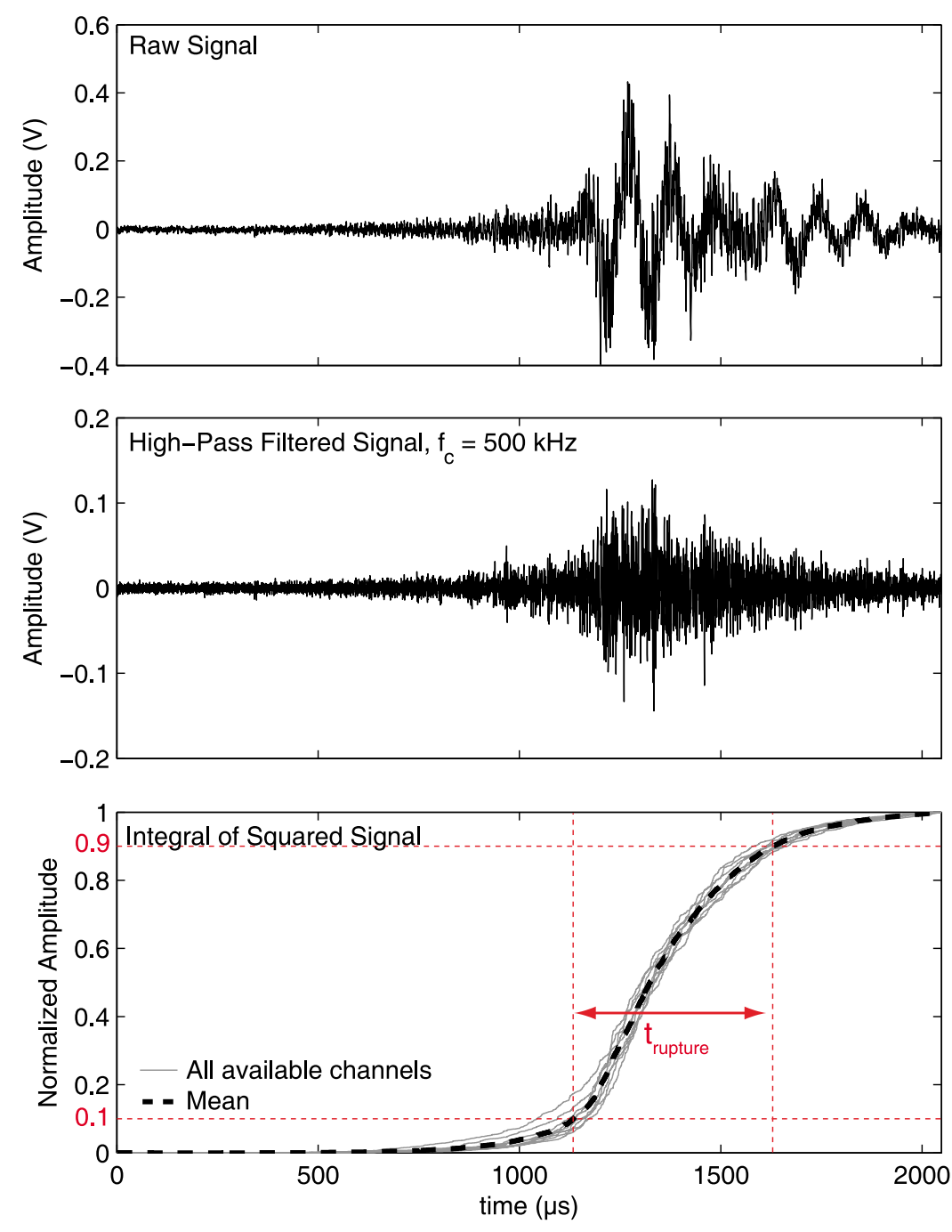

Figure 17. Processing of low-frequency events to retrieve the rupture duration. (top) The raw signal is filtered with a high-pass, first-order Butterworth filter (cutoff frequency $500 \mathrm{kHz}$ ). (middle) The square of the resulting waveform is integrated, and the baseline corresponding to noise is removed. The signal on each channel is normalized. (bottom) The result (light gray lines). The dashed line is the mean of all available channels. The rupture duration $t_{\text {rupture }}$ is estimated by the time from the processed signal to rise from 0.1 to 0.9 . This time corresponds to the release of $80 \%$ of the high-frequency energy of the waveforms.

value is negligible compared to the background temperature, and even at $70^{\circ} \mathrm{C}$ it is far from the dehydration temperature of gypsum.

[49] The major difference in the signals between room temperature and $70^{\circ} \mathrm{C}$ tests may thus be explained by the propagation speed of the shear band. From a mechanical and microstructural point of view, the processes are likely to be the same at both temperatures. The driving process of shear band formation at elevated pressure seems to be grain kinking: a plastic phenomenon. It involves motion of dislocations, which is very sensitive to temperature. The propagation of a shear band may encounter numerous obstacles: grain boundaries, misoriented grains that cannot easily kink or cleave. At low temperature, these obstacles slow down the propagation and it takes a significant time for plasticity to act and for the shear band to propagate. At elevated temperatures, those plastic processes are much faster and thus the shear band can form quicker. Such an explanation is qualitative only, but explains why stress drops and shear bands induce a large-amplitude $\mathrm{AE}$ at $70^{\circ} \mathrm{C}$ and do not at room temperature.

[50] The event displayed in Figure 14g seems to occur in two phases, which may be attributed to the nucleation process. Phase I could be understood as a relatively slow coalescence of microcracks, similar to what is seen during the event shown in Figure 14c. At some point (phase II), the process accelerates and starts radiating higher energy. This acceleration point could correspond to a highly stressed zone encountered by the shear band during its propagation, thus releasing higher elastic energy during its breakdown [Rubinstein et al., 2004].

[51] In order to estimate a magnitude for each event, the peak intensity of the low-frequency waveforms can be collected for all stress drop events during high-temperature 

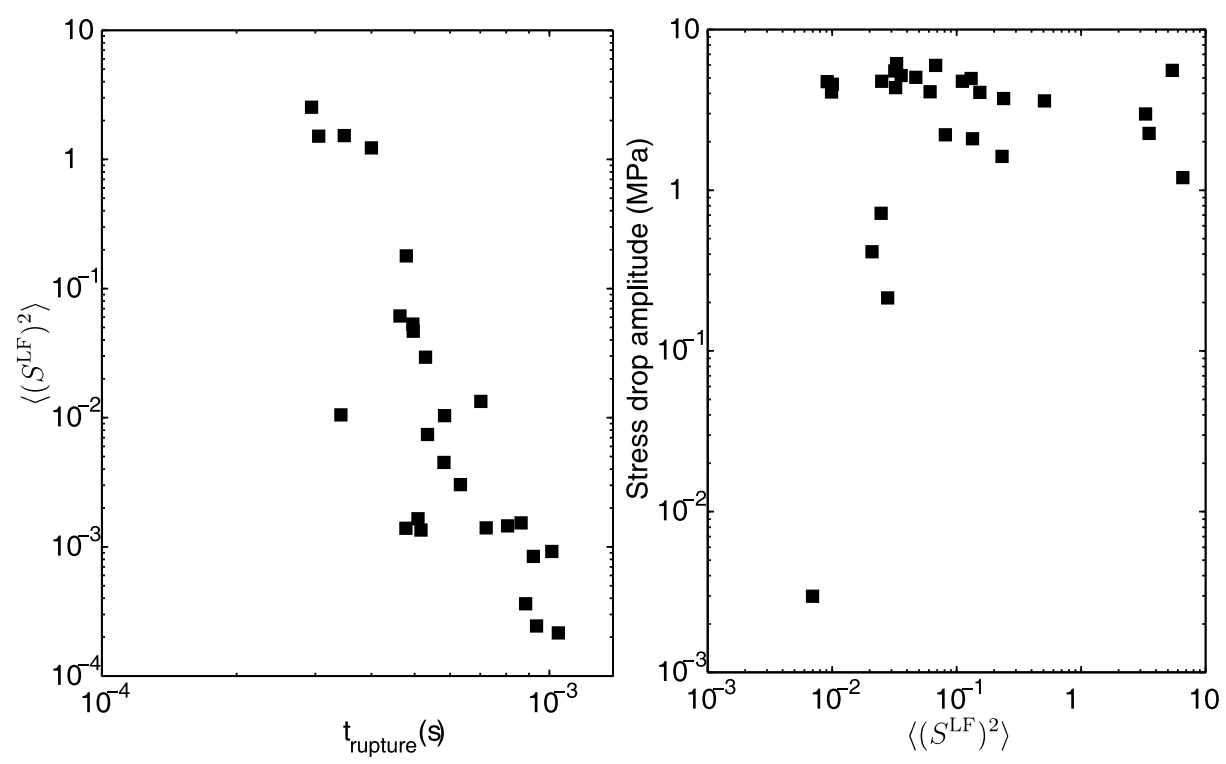

Figure 18. Scaling between waveform maximum amplitude, rupture duration, and static stress drop amplitude. The raw signals are filtered with a low-pass first-order Butterworth filter at a cutoff frequency of $20 \mathrm{kHz}$, and the maximum amplitude of the square of this filtered signal is collected. The data suggest a negative correlation to $t_{\text {rupture }}$. However, the static stress drop amplitude seems to be independent of the signal amplitude.

tests. The raw signals are filtered with a first-order, low-pass Butterworth filter at a cutoff frequency of $20 \mathrm{kHz}$. To avoid possible polarity differences from one channel to another, the filtered signals $S_{i}^{\mathrm{HF}}(t)$ are squared, and the maximum of $\left(S_{i}^{\mathrm{LF}}(t)\right)^{2}$ is extracted. The average amplitude,

$$
\left\langle\left(S^{\mathrm{LF}}\right)^{2}\right\rangle=\frac{1}{N} \sum_{i=1}^{N} \max \left\{\left(S_{i}^{\mathrm{LF}}(t)\right)^{2}\right\},
$$

over the $N$ channels is then calculated. Figure 18 reports this amplitude as a function of $t_{\text {rupture }}$ for the test performed at $P_{\mathrm{c}}=50 \mathrm{MPa}$. There is a general trend showing a negative correlation between the maximum amplitude and the rupture duration. The faster the rupture, the larger the amplitude of the waves. This is qualitatively consistent with the fact that seismic efficiency is generally an increasing function of the rupture speed [e.g., Kanamori and Brodsky, 2004]. We also tried to correlate the maximum amplitude at low frequency $\left\langle\left(S^{\mathrm{LF}}\right)^{2}\right\rangle$ (as defined in equation (4)) with the amplitude of the stress drop as recorded by the axial stress measurement (Figure 18, right). There is no correlation, which indicates that the static stress drop is not related to the dynamics of the rupture process. This is consistent with the seismological estimates of stress drops that are found to be independent of the earthquakes' magnitude [e.g., Kanamori and Anderson, 1975], but are more variable for small earthquakes [e.g., Allmann and Shearer, 2007, 2009].

\subsection{Comparison With Other Rocks}

[52] During the shear banding, our data combination ranging from mechanics, microstructure, wave velocity, and acoustic emissions allows us to observe phenomena occurring at two scales. At the microscopic grain scale, we observe the interplay between plastic deformation (kinks) and microcrack opening. These processes produce highfrequency AE that we record on the PZTs. At the macroscopic scale, the propagation of the band itself induces a stress drop, and at elevated temperature the propagation is fast enough to radiate elastic energy at low frequency. In typical fracture tests on brittle rocks such as granite, two cases are met: If the rock is intact, acoustic emission signals correspond only to microcracking and can be used to delineate the fracture plane [e.g., Scholz, 1968; Mogi, 1968; Lockner and Byerlee, 1977]. The samples are usually too small for the fracture to accelerate and the macroscopic fracture never propagates dynamically to radiate low-frequency waves [Ohnaka and Shen, 1999; Ohnaka, 2003]. If the rock is already fractured or saw cut, stick-slip events are observed and the signal coming from the macroscopic fracture propagation is so large that the microcracking cannot be detected at the same time [Thompson et al., 2005, 2009]. In the case of Volterra gypsum, the macroscopic failure (or shear banding) is dynamic but does not hide the high-frequency signals coming from the microcracks. In this material, the critical fault length above which fault propagation becomes dynamic [Ohnaka, 2003] is smaller than or of the same order of magnitude as the size of the sample $(\sim 5-10 \mathrm{~cm})$. However, it is still unclear whether we observe a high-velocity fault propagation or an accelerating fault at the transition from quasi-static to dynamic rupture. Our estimates of rupture speed, from 50 to $200 \mathrm{~m} \mathrm{~s}^{-1}$, may suggest the latter.

[53] In Figure 19, the typical stress-strain curves of rocks (in gray) are reported for the transition from brittle, strainweakening to ductile, strain-hardening behavior. In the case of gypsum (in black), increasing temperature at elevated confining pressure produces an unstable ductile behavior. Our experiments suggest that dynamic events can propagate within the ductile field of gypsum because the driving 


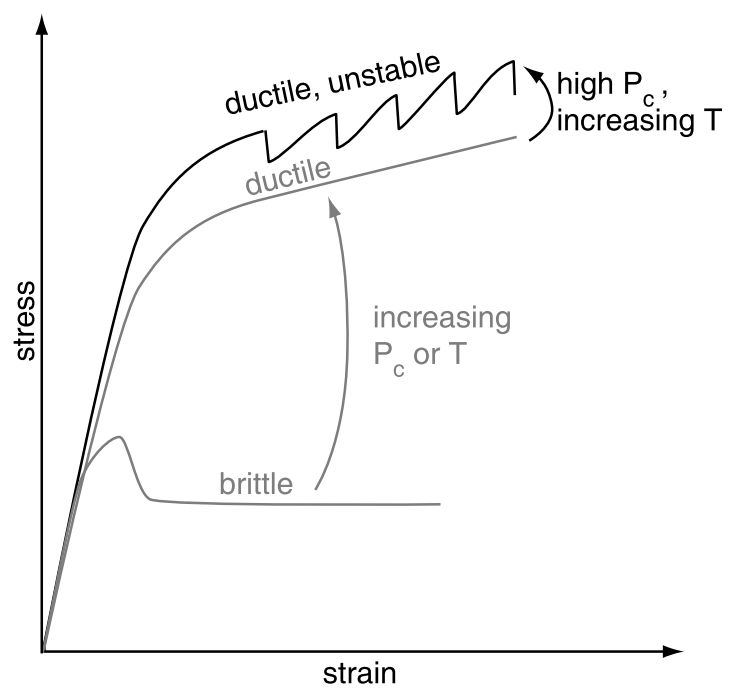

Figure 19. The brittle-ductile transition for typical rocks (in gray) and the case of gypsum (in black). Usually, increasing pressure and temperature make the rocks switch from brittle and strain-weakening to ductile and strain-hardening behavior. In the case of gypsum, a slight increase in temperature at elevated pressure makes this material change from a relatively smooth, ductile behavior to a ductile but highly unstable behavior.

process of shear banding is a plastic phenomenon. This may be evidence of the possibility of plastically induced dynamic shear banding.

[54] To what extent can we extrapolate this behavior to the natural case? Two conditions would be required: (1) The microscopic processes identified in gypsum must exist in other common types of rocks at depth and (2) fault zone irregularities and rock heterogeneity should not hamper those processes from being active. This restrains considerably the range of rocks and settings in which extrapolations can be done. The rocks must behave in a semibrittle manner with only few intracrystalline slip systems available. The ambient temperature and pressure should be elevated enough to activate these slip systems, but not high enough to trigger any mineral phase change. Such description might correspond to rocks containing minerals such as serpentines, talc, or olivine, e.g., a subducting oceanic crust. Indeed, serpentinites can also be kinked [e.g., Viti and Hirose, 2009], as can talc [Escartín et al., 2008] and olivine [e.g., Green and Radcliffe, 1972]. At elevated pressure and temperature those minerals may localize deformation in a similar way as the gypsum we studied. However, further experimental investigations are needed to make sure that deformation processes in these rocks are similar to those of gypsum (e.g., the work by Escartín et al. [2008] on talc).

\section{Conclusion}

[55] The experimental data presented in this work showed that gypsum experiences a transition from brittle to semibrittle behavior between $10 \mathrm{MPa}$ and $20 \mathrm{MPa}$ confining pressure. Temperature up to $70^{\circ} \mathrm{C}$ has little influence on this behavior. The semibrittle behavior consists in the formation of multiple shear bands mainly composed of kinked gypsum grains and microcracks. Elastic wave velocities decrease during deformation, which can be attributed to the opening and propagation of microcracks in the samples. Due to the vertical differential stress, these cracks are preferably vertically oriented. There is a linear correlation between crack density evolution and axial deformation: The material can accumulate microcracks while hardening and without losing its integrity. This is typical of semibrittle behavior. Gypsum is thus a suitable material to study the brittle-ductile transition in the laboratory.

[56] At elevated pressure and temperature, shear banding is dynamic and produces a low-frequency acoustic event. Within the signal, high-frequency content may correspond to the damage associated with the creation of the shear band. The time during which this damage is created can be used to estimate the propagation time of the shear band. The corresponding rupture speeds range from $50 \mathrm{~m} \mathrm{~s}^{-1}$ to $200 \mathrm{~m} \mathrm{~s}^{-1}$.

[57] The fact that shear banding is dynamic at elevated temperature but silent at room temperature points out that gypsum behaves anomalously compared to other rocks. This anomaly may arise from the fact that a plastic microprocess, namely, grain kinking, is a driving process in the shear band formation.

[58] The slow and silent shear banding at room temperature and high pressure could correspond to an aseismic behavior, analogous to silent and/or slow slip events [e.g., Ide et al., 2007], whereas at high temperature the rapid and dynamic ruptures could be understood as a seismic behavior, either producing nonvolcanic tremors, low-frequency earthquakes [e.g., Ide et al., 2007], or simply regular earthquakes. Our set of experiments is obviously too specific to draw strong general conclusions with regard to what may happen in nature. However, this opens the possibility that earthquakes may be generated at the brittle-ductile transition, and that microplasticity may help to generate dynamic stress drops.

\section{Appendix A}

[59] In this appendix we present the method to estimate crack density from $P$ and $S$ wave measurements. First, the uncracked moduli $E_{0}$ and $\nu_{0}$ are obtained by inverting the velocity data obtained at $95 \mathrm{MPa}$ hydrostatic stress, using

$$
\begin{gathered}
\nu_{0}=\left(\frac{1}{2}\left(\frac{V_{\mathrm{p}}}{V_{\mathrm{s}}}\right)^{2}-1\right) /\left(\left(\frac{V_{\mathrm{p}}}{V_{\mathrm{s}}}\right)^{2}-1\right), \\
E_{0}=2 \rho\left(1+\nu_{0}\right) V_{\mathrm{s}}^{2},
\end{gathered}
$$

where $\rho$ is the rock density. With $V_{\mathrm{p}}=5500 \mathrm{~m} \mathrm{~s}^{-1}, V_{\mathrm{s}}=$ $3100 \mathrm{~m} \mathrm{~s}^{-1}$ and $d=2300 \mathrm{~kg} \cdot \mathrm{m}^{-3}$ we get $E_{0} \approx 5.6 \times 10^{10} \mathrm{~Pa}$ and $\nu_{0} \approx 0.27$.

[60] The forward problem consists in calculating the wave velocities in different directions as a function of the crack density tensor $\alpha$. This tensor can be written

$$
\alpha=\left(\begin{array}{ccc}
\alpha_{11} & 0 & 0 \\
0 & \alpha_{22} & 0 \\
0 & 0 & \alpha_{33}
\end{array}\right),
$$


where the subscript number indicates the orientation of the vector normal to the cracks plane. In the case of a transversely isotropic crack distribution oriented by axis 3 , the vertical crack densities are $\alpha_{11}=\alpha_{22}$ and the horizontal crack density is $\alpha_{33}$. For dry rocks, Sayers and Kachanov [1995] established an approximate scheme relation between the stiffness tensor $C$ and $\alpha$, in the case of transversely isotropic crack distribution:

$$
\begin{gathered}
C_{11}+C_{12}=\left(1 / E_{0}+\alpha_{33}\right) / D, \\
C_{11}-C_{12}=1 /\left(\left(1+\nu_{0}\right) / E_{0}+\alpha_{11}\right), \\
C_{33}=\left(\left(1-\nu_{0}\right) / E_{0}+\alpha_{11}\right) / D, \\
C_{44}=1 /\left(2\left(1+\nu_{0}\right) / E_{0}+\alpha_{11}+\alpha_{33}\right), \\
C_{13}=\left(\nu_{0} / E_{0}\right) / D, \\
C_{66}=1 /\left(2\left(1+\nu_{0}\right) / E_{0}+2 \alpha_{11}\right),
\end{gathered}
$$

where the Voigt (two-index) notation is used and

$$
D=\left(1 / E_{0}+\alpha_{33}\right)\left(\left(1-\nu_{0}\right) / E_{0}+\alpha_{11}\right)-2\left(\nu_{0} / E_{0}\right)^{2} .
$$

From the effective stiffness tensor, we calculate the wave phase velocity along the propagation angles $\phi$ corresponding to our sensors setup:

$$
\begin{gathered}
V_{\mathrm{p}}(\phi)=\left\{\left(C_{11} \sin ^{2} \phi+C_{33} \cos ^{2} \phi+C_{44}+\sqrt{M}\right) /(2 \rho)\right\}^{1 / 2}, \\
V_{\mathrm{sh}}(\phi)=\left\{\left(C_{11} \sin ^{2} \phi+C_{33} \cos ^{2} \phi+C_{44}-\sqrt{M}\right) /(2 \rho)\right\}^{1 / 2},
\end{gathered}
$$

$$
V_{\mathrm{sv}}(\phi)=\left\{\left(C_{66} \sin ^{2} \phi+C_{44} \cos ^{2} \phi\right) / \rho\right\}^{1 / 2},
$$

where

$$
\begin{aligned}
M= & \left(\left(C_{11}-C_{44}\right) \sin ^{2} \phi-\left(C_{33}-C_{44}\right) \cos ^{2} \phi\right)^{2} \\
& +\left(\left(C_{13}+C_{44}\right) \sin (2 \phi)\right)^{2} .
\end{aligned}
$$

Formally, we obtain a function $\mathbf{V}\left(\alpha_{11}, \alpha_{33}\right)$ that allows us to calculate synthetic data.

[61] In the case of an oblique path in a transversely isotropic medium, the measured wave velocity is the group velocity and not the phase velocity. It may induce an error of the order of $10 \%$ [Sarout, 2006] in the calculation of elastic moduli. We do not take this complexity into account in our inversion process. Since the sensors' configuration and ray angles are similar in all tests, our approximate calculations can be used to compare experiments with good confidence.

[62] The uncertainty on the velocity data $\mathbf{V}_{\text {obs }}$ is assumed to be $\sigma_{\mathrm{V}}=100 \mathrm{~m} \mathrm{~s}^{-1}$. We use the general discrete inverse problem theory as defined by Tarantola [2005] that as- sociates a data point with a probability density. We assume a Laplace (double-exponential) probability density distribution because of the robustness of the $\ell_{1}$-norm. The model space $\left(\alpha_{11}, \alpha_{33}\right)$ is fully explored and the posterior probability density,

$$
p_{\text {post }}\left(\alpha_{11}, \alpha_{33}\right)=\exp \left(-\frac{\left\|\mathbf{V}\left(\alpha_{11}, \alpha_{33}\right)-\mathbf{V}_{\text {obs }}\right\|}{\sigma}\right),
$$

is computed. The position $\left(\alpha_{11}^{*}, \alpha_{33}^{*}\right)$ of this maximum corresponds to the best solution in the sense of least absolute values criterion. The error of the resulting solution is estimated by calculating the range of crack density and mean orientation that keep $p_{\text {post }}$ greater or equal to $60 \%$ of its maximum value.

[63] Acknowledgments. We are grateful to Fabrice Brunet, Ernest Rutter, Luigi Burlini, and R. Paul Young for helpful discussions; to Will Pettitt from ASC Ltd. for his help on the acoustic monitoring system; and to Nathaniel Findling, Yves Pinquier, and Thierry Descamps for technical support. Sanchez Technologies' staff is thanked for their support on the triaxial apparatus. Comments by two anonymous reviewers and an Associate Editor greatly improved the manuscript. This work was financially supported by INSU program 3 F (Failles, Fluides, Flux).

\section{References}

Allmann, B. P., and P. M. Shearer (2007), Spatial and temporal stress drop variations in small earthquakes near Parkfield, California, J. Geophys. Res., 112, B04305, doi:10.1029/2006JB004395.

Allmann, B. P., and P. M. Shearer (2009), Global variations of stress drop for moderate to large earthquakes, J. Geophys. Res., 114, B01310, doi:10.1029/2008JB005821.

Ayling, M. R., P. G. Meredith, and S. A. F. Murrell (1995), Microcracking during triaxial deformation of porous rocks monitored by changes in rock physical properties, I. Elastic-wave propagation measurements on dry rocks, Tectonophysics, 245, 205-221.

Barberini, V., L. Burlini, E. H. Rutter, and M. Dapiaggi (2005), High-strain deformation tests on natural gypsum aggregates in torsion, in HighStrain Zones: Structure and Physical Properties, edited by D. Bruhn and L. Burlini, Geol. Soc. Spec. Publ., 245, 277-290.

Baud, P., A. Schubnel, and T.-F. Wong (2000), Dilatancy, compaction, and failure mode in Solnhofen limestone, J. Geophys. Res., 105(B8), 19,289-19,303, doi:10.1029/2000JB900133.

Baud, P., E. Klein, and T.-F. Wong (2004), Compaction localization in porous sandstones: Spatial evolution of damage and acoustic emission activity, J. Struct. Geol., 26, 603-624.

Brace, W. F., and J. D. Byerlee (1966), Stick-slip as a mechanism for earthquakes, Science, 153, 990-992.

Brace, W. F., and D. L. Kohlstedt (1980), Limits on lithospheric stress imposed by laboratory experiments, J. Geophys. Res., 85(B11), 6248-6252, doi:10.1029/JB085iB11p06248.

Brace, W. F., B. W. Paulding, and C. Scholz (1966), Dilatancy in the fracture of crystalline rocks, J. Geophys. Res., 71(16), 3939-3953, doi:10.1029/JZ071i016p03939.

Brown, L. S. (1931), Cap-rock petrography, AAPG Bull., 15, 509-529.

Escartín, J., M. Andreani, G. Hirth, and B. Evans (2008), Relationships between the microstructural evolution and the rheology of talc at elevated pressures and temperatures, Earth Planet. Sci. Lett., 268, 463-475.

Evans, B., J. T. Fredrich, and T.-F. Wong (1990), The brittle-ductile transition in rocks: Recent experimental and theoretical progress, in The BrittleDuctile Transition in Rocks: The Heard Volume, Geophys. Monogr. Ser., vol. 56, edited by A. G. Duba et al., pp. 1-20, AGU, Washington, D. C.

Fortin, J., S. Stanchits, G. Dresen, and Y. Guéguen (2006), Acoustic emission and velocities associated with the formation of compaction bands in sandstone, J. Geophys. Res., 111, B10203, doi:10.1029/2005JB003854.

Fredrich, J. T., B. Evans, and T.-F. Wong (1989), Micromechanics of the brittle to plastic transition in Carrara marble, J. Geophys. Res., 94(B4), 4129-4145, doi:10.1029/JB094iB04p04129.

Green, H. W., II, and S. V. Radcliffe (1972), Dislocation mechanisms in olivine and flow in the upper mantle, Earth Planet. Sci. Lett., 15, 239-247.

Gupta, I. N. (1973), Seismic velocities in rock subjected to axial loading up to shear fracture, J. Geophys. Res., 78(29), 6936-6942, doi:10.1029/ JB078i029p06936. 
Hadizadeh, J., and E. H. Rutter (1983), The low temperature brittle-ductile transition in a quartzite and the occurence of cataclastic flow in nature, Geol. Rundsch., 72, 493-509.

Handin, J., and R. Hager (1957), Experimental deformation of sedimentary rocks under confining pressure: Tests at room temperature on dry sample, Am. Assoc. Pet. Geol. Bull., 41, 1-50.

Heard, H. C. (1960), Transition from brittle fracture to ductile flow in Solhofen limestone as a function of temperature, confining pressure and interstitial fluid pressure, in Rock Deformation, edited by D. T Griggs and J. Handin, pp. 193-226, Geol. Soc. of Am., New York.

Heard, H. C., and W. W. Rubey (1966), Tectonic implications of gypsum dehydration, Geol. Soc. Am. Bull., 77, 741-760.

Ide, S., G. C. Beroza, D. R. Shelly, and T. Uchide (2007), A scaling law for slow earthquakes, Nature, 447, 76-79, doi:10.1038/nature05780.

Jaeger, J. C., and N. G. W. Cook (1969), Fundamentals of Rock Mechanics, 1 st ed., Methuen, London.

Kanamori, H., and D. L. Anderson (1975), Theoretical basis of some empirical relations in seismology, Bull. Seismol. Soc. Am., 65(5), 1073-1095.

Kanamori, H., and E. Brodsky (2004), The physics of earthquakes, Rep. Prog. Phys., 67, 1429-1496.

Ko, S.-C., D. L. Olgaard, and U. Briegel (1995), The transition from weakening to strengthening in dehydrating gypsum: Evolution of excess pore pressures, Geophys. Res. Lett., 22(9), 1009-1012, doi:10.1029/ 95GL00886.

Ko, S.-C., D. L. Olgaard, and T.-F. Wong (1997), Generation and maintenance of pore pressure excess in a dehydrating system: 1. experimental and microstructural observations, J. Geophys. Res., 102(B1), 825-839, doi:10.1029/96JB02485.

Laubscher, H. P. (1975), Viscous components of Jura folding, Tectonophysics, 27, 239-254.

Laughner, J. W., T. W. Cline, R. E. Newnham, and L. E. Cross (1979), Acoustic emissions from stress-induced dauphiné twinning in quartz, $J$. Phys. Chem. Min., 4, 129-137.

Lockner, D., and J. Byerlee (1977), Acoustic emission and creep in rock at high confining pressure and differential stress, Bull. Seismol. Soc. Am. 67(2), 247-258.

Lockner, D. A., J. B. Walsh, and J. D. Byerlee (1977), Changes in seismic velocity and attenuation during deformation of granite, J. Geophys. Res., 82(33), 5374-5378, doi:10.1029/JB082i033p05374.

Lockner, D. A., J. D. Byerlee, V. Kuksenko, A. Ponomarev, and A. Sidorin (1992), Observation of quasistatic fault growth from acoustic emissions, in Fault Mechanics and Transport Properties of Rocks, Int. Geophys. Ser., vol. 51, edited by B. Evans and T. F. Wong, pp. 3-31, Academic, London.

Malavieille, J., and J. F. Ritz (1989), Mylonitic deformation of evaporites in decollements: Examples from the Southern Alps, France, J. Struct. Geol., 11, 583-590.

Milsch, H., and C. H. Scholz (2005), Dehydration-induced weakening and fault slip in gypsum: Implications for the faulting process at intermediate depth in subduction zones, J. Geophys. Res., 110, B04202, doi:10.1029/ 2004JB003324.

Mogi, K. (1968), Source locations of elastic shocks in the fracturing process in rocks (1), Bull. Earthquake Res. Inst. Univ. Tokyo, 46, 1103-1125.

Ohnaka, M. (2003), A constitutive scaling law and a unified comprehension for frictional slip failure, shear fracture of intact rock, and earthquake rupture, J. Geophys. Res., 108(B2), 2080, doi:10.1029/2000JB000123.

Ohnaka, M., and L. Shen (1999), Scaling of the shear rupture process from nucleation to dynamic propagation: Implications of geometry irregularity of the rupturing surfaces, J. Geophys. Res., 104(B1), 817-844, doi:10.1029/1998JB900007.

Olgaard, D. L., S.-C. Ko, and T.-F. Wong (1995), Deformation and pore pressure in dehydrating gypsum under transiently drained conditions, Tectonophysics, 245, 237-248.

Paterson, M. S., and T. F. Wong (2005), Experimental Rock Deformation: The Brittle Field, 2nd ed., Springer, Berlin.

Rosakis, A. J., O. Samudrala, and D. Coker (1999), Cracks faster than the shear wave speed, Science, 284, 1337-1340.
Rubinstein, S. M., G. Cohen, and J. Fineberg (2004), Detachment fronts and the onset of dynamic friction, Nature, 430, 1005-1009.

Sarout, J. (2006), Propriétés physiques et anisotropie des roches argileuses: Modélisation micromécanique et expériences triaxiales, $\mathrm{Ph} . \mathrm{D}$. thesis, École Normale Supérieure, Univ. Paris XI, Orsay, France.

Sayers, C., and M. Kachanov (1995), Microcrack-induced elastic wave anisotropy of brittle rocks, J. Geophys. Res., 100(B3), 4149-4156, doi:10.1029/94JB03134.

Scholz, C. H. (1968), Experimental study of the fracturing process in brittle rocks, J. Geophys. Res., 73(4), 1447-1454, doi:10.1029/ JB073i004p01447.

Schubnel, A., O. Nishizawa, K. Masuda, X. J. Lei, Z. Xue, and Y. Guéguen (2003), Velocity measurements and crack density determination during wet triaxial experiments on Oshima and Toki granites, Pure Appl. Geophys., 160, 869-887.

Schubnel, A., J. Fortin, L. Burlini, and Y. Guéguen (2005), Damage and recovery of calcite rocks deformed in the cataclastic regime, in HighStrain Zones: Structure and Physical Properties, edited by D. Bruhn and L. Burlini, Geol. Soc. Spec. Publ., 245, 203-221.

Schubnel, A., E. Walker, B. D. Thompson, J. Fortin, Y. Guéguen, and R. P. Young (2006), Transient creep, aseismic damage and slow failure in Carrara marble deformed across the brittle-ductile transition, Geophys. Res. Lett., 33, L17301, doi:10.1029/2006GL026619.

Schubnel, A., B. D. Thompson, J. Fortin, Y. Guéguen, and R. P. Young (2007), Fluid-induced rupture experiment on Fontainebleau sandstone: Premonitory activity, rupture propagation, and aftershocks, Geophys. Res. Lett., 34, L19307, doi:10.1029/2007GL031076.

Sibson, R. H. (1982), Fault zone models, heat flow, and the depth distribution of earthquakes in the continental crust of the United States, Bull. Seismol. Soc. Am., 72, 151-163.

Stretton, I. C. (1996), An experimental investigation of the deformation properties of gypsum, Ph.D. thesis, Univ. of Manchester, Manchester, U. K.

Tarantola, A. (2005), Inverse Problem Theory, 2nd ed., SIAM, Philadelphia, Pa.

Thompson, B. D., R. P. Young, and D. A. Lockner (2005), Observations of premonitory acoustic emission and slip nucleation during a stick slip experiment in smooth faulted Westerly granite, Geophys. Res. Lett., 32 L10304, doi:10.1029/2005GL022750.

Thompson, B. D., R. P. Young, and D. A. Lockner (2006), Fracture in Westerly granite under AE feedback and constant strain rate loading: Nucleation, quasi-static propagation, and the transition to unstable fracture propagation, Pure Appl. Geophys., 163, 995-1019.

Thompson, B. D., R. P. Young, and D. A. Lockner (2009), Premonitory acoustic emissions and stick-slip in natural and smooth-faulted Westerly granite, J. Geophys. Res., 114, B02205, doi:10.1029/2008JB005753.

Thomsen, L. (1986), Weak elastic anisotropy, Geophysics, 51(10), 1954-1966.

Tullis, J., and R. A. Yund (1992), The brittle ductile transition in feldspar aggregates: An experimental study, in Fault Mechanics and Transport Properties of Rocks, Int. Geophys. Ser., vol. 51, edited by B. Evans and T.-F. Wong, pp. 89-117, Academic, London.

Turner, F. J., and L. E. Weiss (1965), Deformational kinks in burcite and gypsum, Proc. Natl. Acad. Sci. USA, 54, 359-364.

Viti, C., and T. Hirose (2009), Dehydration reactions and micro/nanostructures in experimentally-deformed serpentinites, Contrib. Mineral. Petrol., 157, 327-338, doi:10.1007/s00410-008-0337-6.

Weiss, J., and J.-R. Grasso (1997), Acoustic emission in single crystals of ice, J. Phys. Chem. B, 101(32), 6113-6117.

Wong, T.-F., S.-C. Ko, and D. L. Olgaard (1997), Generation and maintenance of pore pressure excess in a dehydrating system: 2 . Theoretical analysis, J. Geophys. Res., 102(B1), 841-852, doi:10.1029/96JB02484

N. Brantut, A. Schubnel, and Y. Guéguen, Laboratoire de Géologie, École Normale Supérieure, CNRS UMR 8538, 24 rue Lhomond, F-75231 Paris CEDEX 05, France. (nicolas.brantut@ens.fr) 